\title{
Recent Advances in Phenol Dearomatization and Its Application in Complex Syntheses
}

\author{
Qiuping Ding, ${ }^{a}$ Yang Ye, ${ }^{b}$ Renhua Fan*b \\ a Key Laboratory of Functional Small Organic Molecules, Ministry of Education, Jiangxi Normal University, Nanchang 330022, P. R. of China \\ b Department of Chemistry, Fudan University, 220 Handan Road, Shanghai 200433, P. R. of China \\ Fax+86(21)65642412; E-mail: rhfan@fudan.edu.cn
}

Received: 15.09.2012; Accepted after revision: 22.10 .2012

\begin{abstract}
As a powerful tool, the dearomatization of phenols has been explored extensively and utilized by organic chemists during the course of complex syntheses. This review highlights recent advances in phenol dearomatizations, especially those accomplished in an enantioselective manner, and the application of dearomatization strategies in complex syntheses.

1 Introduction

2 New Developments in Phenol Dearomatization

3 Enantioselective Phenol Dearomatization

3.1 Controlled by Chiral Substrate

3.2 Controlled by Chiral Catalyst

3.3 Controlled by Chiral Hypervalent Iodine

4 Enantioselective Phenol Dearomatization Strategies in Complex Syntheses

4.1 With the Formation of a Carbon-Oxygen Bond

4.2 With the Formation of a Carbon-Carbon Bond

4.3 With the Formation of a Carbon-Nitrogen Bond

5 Conclusion
\end{abstract}

Key words: dearomatization, enantioselectivity, oxidation, phenols, tandem reaction

\section{$1 \quad$ Introduction}

Organic synthesis has reached a considerable level of maturity. Nowadays, almost any complex molecule can be synthesized, and selective functionalizations achieved. However, with ever-tighter resources, efficiency in organic synthesis is becoming more and more important. An ideal synthesis demands simplicity, safety, brevity, environmental friendliness, as well as high selectivity, yield and diversity. ${ }^{1}$

Phenols are the most frequently utilized substrates for dearomatization to access complex molecules. A number of dearomatization strategies have been used by organic chemists to construct fused, bridged and spiro structures. Owing to the high efficiency of these tactics, more and more investigations have focused on this field. ${ }^{2}$

The oxidation of $o$ - and $p$-hydroquinones generally proceeds in methanol solution at room temperature, and the

SYNTHESIS 2013, 45, 0001-0016

Advanced online publication: 07.11.2012

DOI: 10.1055/s-0032-1317575; Art ID: SS-2012-E0721-R

(C) Georg Thieme Verlag Stuttgart · New York

yield of benzoquinones is almost quantitative. ${ }^{3}$ Dearomatization of 4- or 2-substituted phenols in the presence of an appropriate nucleophile $\mathrm{(Nu}$ ) leading to the respective 4,4- or 2,2-disubstituted cyclohexadienones is especially interesting and synthetically useful (Scheme 1). Various nucleophiles, such as water, ${ }^{4}$ alcohols ${ }^{3,5}$ fluoride ion, ${ }^{6}$ carboxylic acids, ${ }^{5 \mathrm{~d}, 7}$ amides, ${ }^{8}$ oximes, ${ }^{9}$ and electron-rich aromatic rings ${ }^{10,11}$ have been used successfully in dearomatization in either an inter- or an intramolecular mode. Besides, the resulting cyclohexadienones are good electrophilic substrates for various reactions, such as the Diels-Alder reaction, 1,4-addition, reduction and [3+2] cyclization. The following section of this report highlights some recent investigations on phenol dearomatizations, especially those accomplished in an enantioselective manner, and their application in complex syntheses.<smiles>CCc1ccc(O)cc1</smiles>

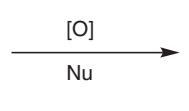<smiles>CC1(C)C=CC(=O)C=C1</smiles>

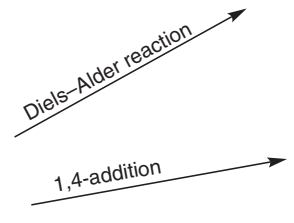<smiles>Oc1ccccc1Br</smiles><smiles>N#CCO</smiles><smiles>[R]C1([N])C=CC=CC1=O</smiles>

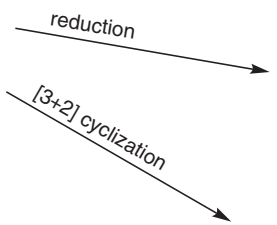

Scheme 1 Dearomatization of 4- or 2-substituted phenols

\section{New Developments in Phenol Dearomatiza- tion}

Besides electron-rich aromatic rings, other carbon resources can be introduced into the cyclohexa-2,5-dienone structure through an oxidative dearomatization process. Canesi and co-workers developed an iodine(III)-mediated oxidative Wagner-Meerwein transposition involving different functionalities (Scheme 2). ${ }^{12}$ The reaction occurred rapidly in hexafluoroisopropanol (HFIP) using iodobenzene diacetate as oxidant. This transformation provides new strategic opportunities to prepare highly functionalized compounds containing a prochiral dienone and a quaternary carbon center connected to several $\mathrm{sp}^{2}$ carbons. 
One year later, the same research group reported a bimolecular oxidative process occurring with carbon-carbon bond formation that has been extended to allylsilanes (Scheme 3). ${ }^{13}$ In this reaction, different 4-alkyl-2-6-disubstituted phenols 19 were successfully oxidized leading to an oxidative variant of the famous Hosomi-Sakurai allylation. ${ }^{11}$ It is noteworthy that the first approach to this reaction was developed by Quideau and co-workers in aprotic solvents with phenyliodine(III) bis(trifluoroacetate) (PIFA), which provided some examples of oxidative allylation on substituted 1-naphthol. ${ }^{14}$

Canesi and co-workers also reported a dearomatization of phenol derivatives that promotes the formation of bicyclic and tricyclic products via a cationic cyclization process. ${ }^{15}$ First, an oxidative vicinal-fused carbocycle formation was performed with a terminal alkyne on a lateral chain at the meta-position of phenol 21. The authors speculated that a strained half-chair intermediate $\mathbf{2 2}$ was generated, and that this strongly favored nucleophile capture, leading to the unsaturated decalin system 24 (Scheme 4). Vicinalfused carbocycles were produced in good yields (43$91 \%$ ). This new process could have application in asymmetric synthesis governed by the benzylic stereogenic center at the meta position (Scheme 5). Such scaffolds are present in numerous natural products such as anominine, ${ }^{16}$ andrographolide, ${ }^{17}$ or the decalin core of azadirachtin. ${ }^{18}$ The cyclization reaction occurred with total stereocontrol in agreement with the configuration of the starting olefin, since a 2:1 mixture of diastereomers was obtained. To verify the high diastereoselectivity of this process, $c i s \mathbf{- 2 5}$ was prepared, and led exclusively to the tricyclic core $\mathbf{2 8}$ in a $43 \%$ yield. Recently, Canesi's research group also reported an oxidative ipso-rearrangement mediated by a hypervalent iodine reagent. A functionalized dienone system containing a quaternary carbon center connected to several $\mathrm{sp}^{2}$ centers was constructed. This transformation was used in the total synthesis of sceletenone, a small alkaloid. ${ }^{19}$

\section{Biographical Sketches}
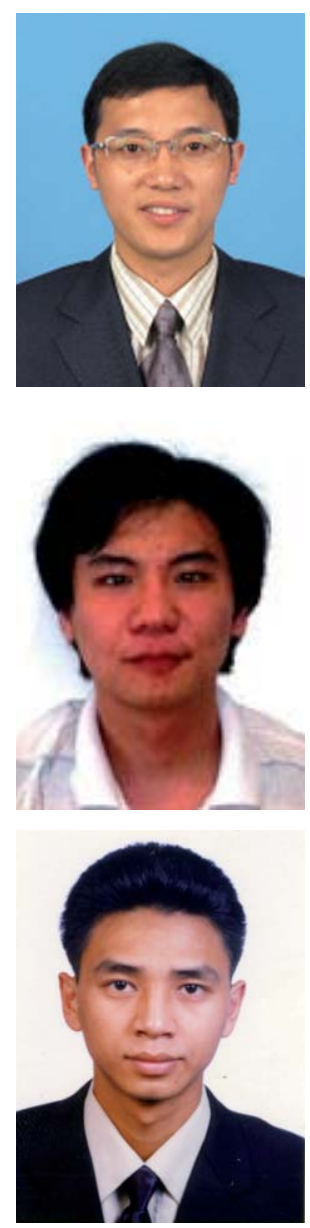

Qiuping Ding was born in Jiangxi, China, in 1975. He received his $\mathrm{Ph} . \mathrm{D}$. from $\mathrm{Fu}-$ dan University under the su-

Yang Ye was born in $\mathrm{Hu}-$ nan, China, in 1985. In 2012, he received his Ph.D.

Renhua Fan was born in Jiangxi, China, in 1976. He received his Ph.D. from Shanghai Institute of Organic Chemistry, Chinese Academy of Sciences under the supervision of Professor pervision of Professor Jie $\mathrm{Wu}$ in 2009 . He is currently an associate professor at Jiangxi Normal University,
China. His research interest is focused on cascade reactions.

from Fudan University under the supervision of Professor Renhua Fan. He is currently a technician in Pharmaron Beijing Co., Ltd.
Xuelong Hou in 2003. After postdoctoral studies (20032006) at Purdue University, USA with Professor Alexander Wei, he moved to Fudan University, China. He is currently a full professor of organic chemistry at the Department of Chemistry of Fudan University. His research interest is focused on hypervalent iodine chemistry. 


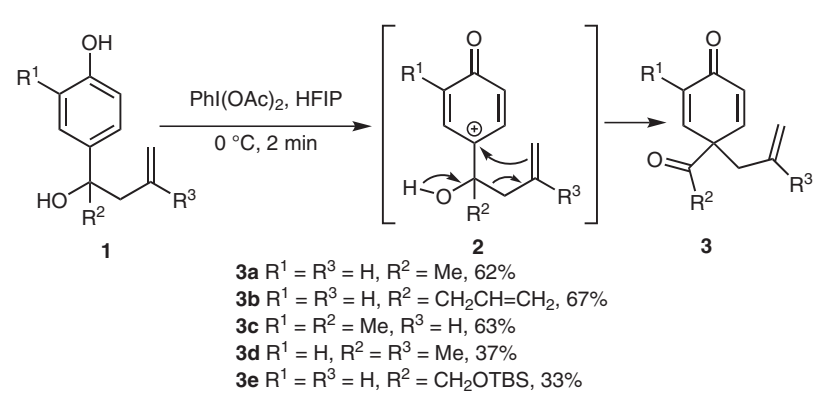



6a $\mathrm{R}^{1}=\mathrm{Me}, \mathrm{R}^{2}=\mathrm{CH}=\mathrm{CH}_{2}, 34 \%$

6b $\mathrm{R}^{1}=\mathrm{Me}, \mathrm{R}^{2}=\mathrm{Ph}, 51 \%$

6c $\mathrm{R}^{1}=\mathrm{Et}, \mathrm{R}^{2}=\mathrm{Ph}, 35 \%$

$6 \mathrm{~d} \mathrm{R}^{1}=\mathrm{Me}, \mathrm{R}^{2}=n-\mathrm{Bu}, 35 \%$

$\underset{{ }^{\circ} \mathrm{C}, 2 \mathrm{~min}}{\stackrel{\mathrm{Phl}(\mathrm{OAc})_{2}, \mathrm{HFIP}}{\longrightarrow}}$

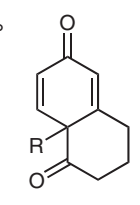

(1)

$\underset{53 \%}{\stackrel{\mathrm{Phl}(\mathrm{OAC})_{2}, \mathrm{HFIP}}{0}}$

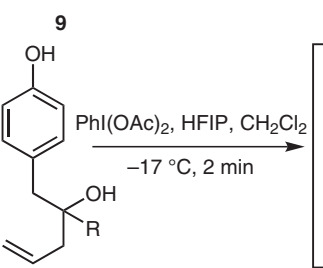

(10)

11

12

13

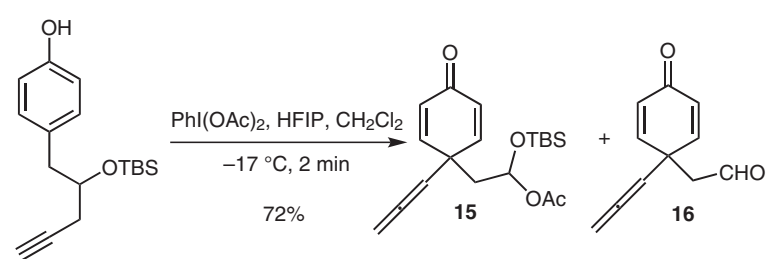

14<smiles>C=CC[C@]1(O)CCCc2cc(Br)c(O)c(Br)c21</smiles>

17

18

Scheme 2 Wagner-Meerwein transposition by dearomatization of phenols

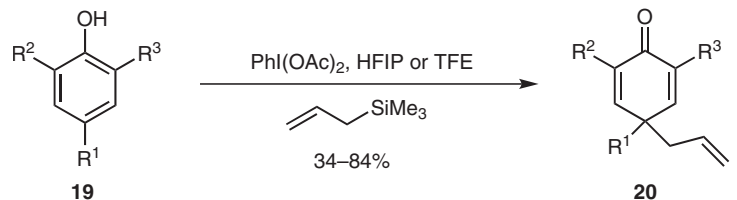

$\mathrm{R}^{1}=\mathrm{Me}, \mathrm{Et}, n-\mathrm{Bu}, \mathrm{CH}_{2} \mathrm{CH}_{2} \mathrm{OH}, i-\mathrm{Pr}, \mathrm{Ph}, \mathrm{CH}_{2} \mathrm{OTBDMS}, \mathrm{CH}_{2} \mathrm{CO}_{2} \mathrm{Me}$ $\mathrm{R}^{2}=t-\mathrm{Bu}, \mathrm{TMS}, \mathrm{Cl}, \mathrm{Br}, \mathrm{I}$

$\mathrm{R}^{3}=t-\mathrm{Bu}, \mathrm{TMS}$

Scheme 3 Bimolecular oxidative process between phenols and allylsilanes

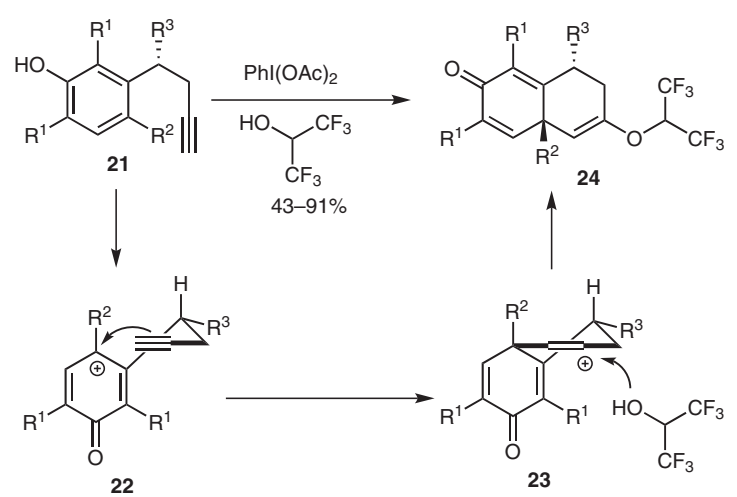

Scheme 4 Oxidative formation of fused carbocycles

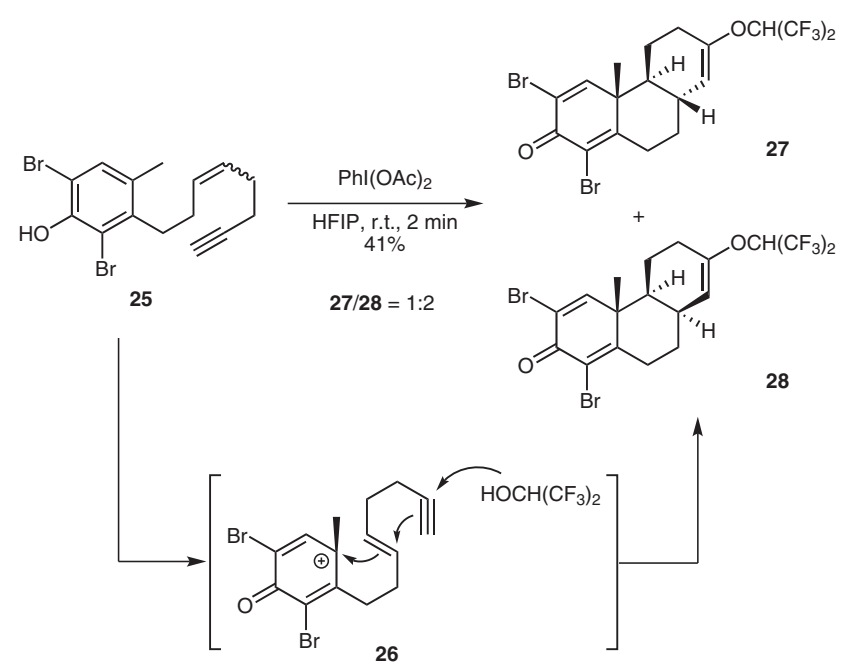

Scheme 5 Asymmetric synthesis of a tricyclic scaffold 
The substituted alkynyl group in $\mathbf{2 9}$, where $\mathrm{R} 2 \neq \mathrm{H}$, also performed as a nucleophile in the carbon-carbon bond formation. Kita and colleagues developed a very effective spirocyclization procedure for installing nucleophiles $\left(\mathrm{Nu}=\mathrm{N}_{3}, \mathrm{NO}_{2}, \mathrm{SCN}, \mathrm{SO}_{2} \mathrm{Tol}\right.$, and $\left.\mathrm{Br}\right)$ induced by iodonium(III) salts (Scheme 6). ${ }^{20}$ The in situ generated cationic iodonium(III) species activates the alkynyl group and induces the ipso-cyclization of compound 29, thereby leading to a spirocyclized iodonium(III) salt. The latter undergoes a reductive coupling ${ }^{21}$ with nucleophiles to afford the functionalized spirocyclic compounds $\mathbf{3 0}$.

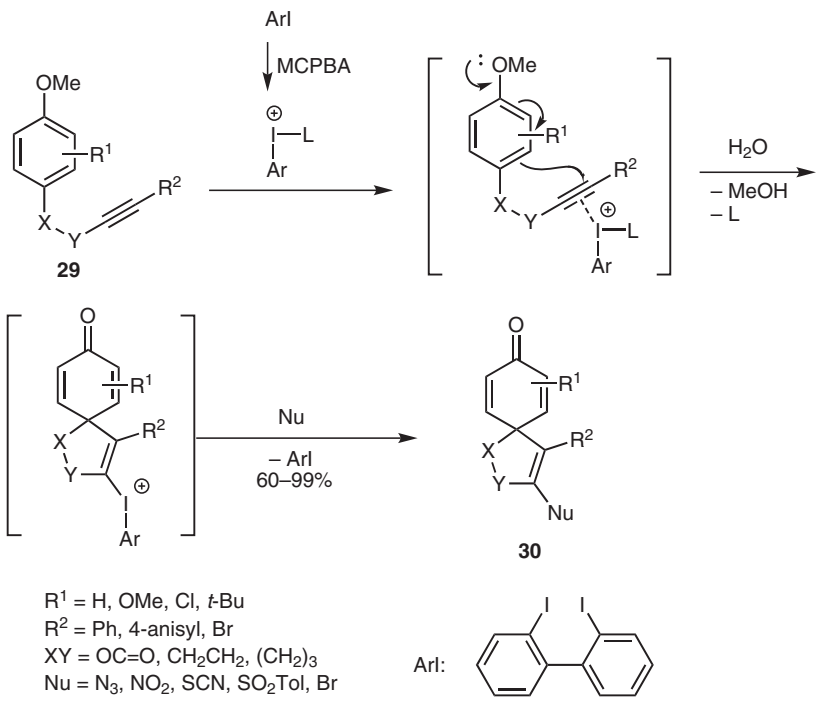

Scheme 6 Synthesis of spirocycles

Zhang and co-workers reported a condition-controlled oxidative dearomatization of phenolic amides (Scheme 7). ${ }^{22}$ In the presence of copper(II) sulfate pentahydrate and 4dimethylaminopyridine (DMAP), the oxidation of phenolic amides with iodobenzene diacetate as oxidant gave rise to highly functionalized spiro $\beta$-lactams. In the absence of copper salts and DMAP, the oxidation provided 4-methoxycyclohexadienones in nearly quantitative yields. After base-catalyzed intramolecular Michael addition and acidcatalyzed rearomatization, oxindoles were formed.

In addition to oxidative dearomatization, a high-valentpalladium-mediated intramolecular cyclization cascade reaction developed by Stephenson and co-workers has been used to prepare spirocyclic cyclohexadienone structures from phenols (Scheme 8). ${ }^{23}$ The resulting spirocyclic cyclohexadienone could be a precursor for a radical

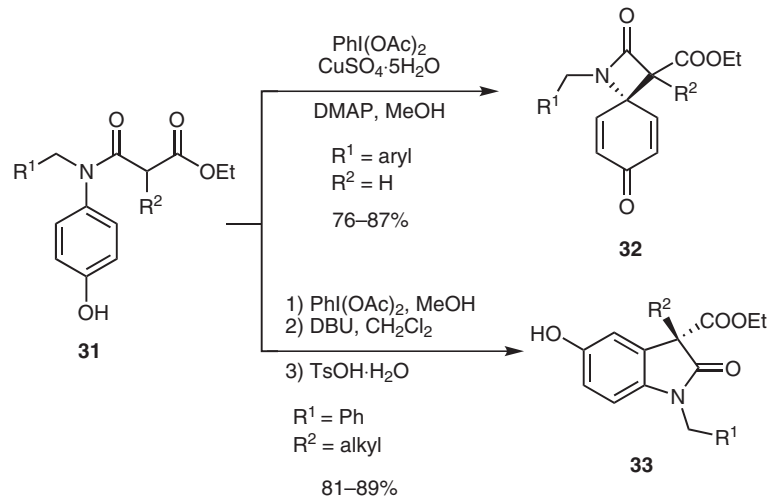

Scheme 7 Synthesis of spirolactams and oxindoles via oxidative dearomatization

conjugate addition to efficiently provide the bicyclic fragment of platensimycin. ${ }^{24} \mathrm{~A}$ plausible catalytic cycle is outlined in Scheme 9. In path A, palladium(II) coordinates to the olefin of the substrate and induces an oxypalladation to form a Wacker intermediate ${ }^{25}$ Metallation of the carbon-hydrogen bond and subsequent oxidation by iodobenzene diacetate provides a palladacycle, which undergoes reductive elimination to produce the $\mathrm{C}-\mathrm{H}$ insertion product 36. For phenols, the catalytic cycle proceeds through a dearomatization pathway (path B). The resulting Wacker intermediate undergoes oxidation to form a highly electrophilic alkylpalladium(IV) intermediate. After reductive nucleophilic substitution by the phenol ring, spirocyclohexadienone product $\mathbf{3 7}$ is formed.

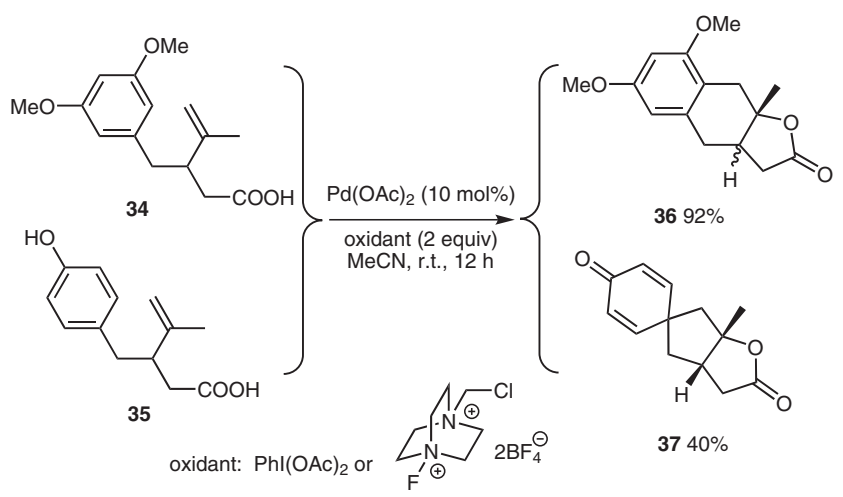

Scheme 8 Synthesis of spirocyclic cyclohexadienones and tricyclic scaffolds 


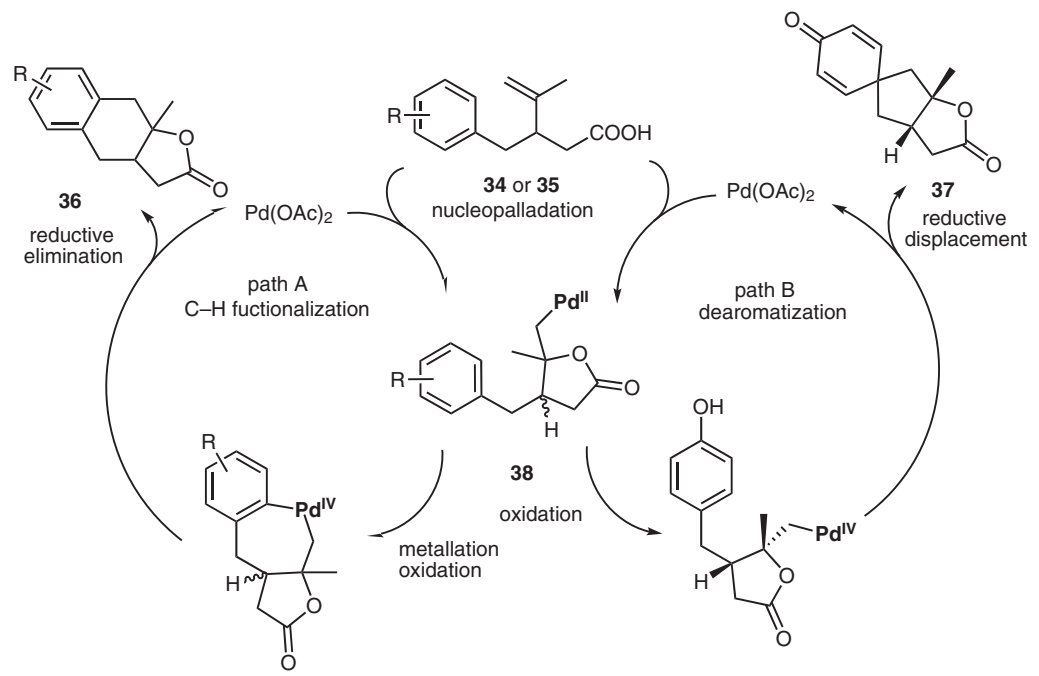

Scheme 9 Mechanism of Pd-mediated cyclization reactions leading to spirocyclic cyclohexadienones and tricyclic scaffolds

\section{Enantioselective Phenol Dearomatization}

\subsection{Controlled by Chiral Substrate}

Quideau and co-workers reported a convenient and enantioselective route to access spiroketals through dearomatization of phenols (Scheme 10). ${ }^{5 a, 26}$ Phenolic alcohols 39a, $, \mathbf{b}, \mathbf{e}, \mathbf{f}, \mathbf{h}$, with a tert-butyl substituent on the carbon atom attached to the hydroxy group in the side chain, underwent a highly diastereoselective transformation, in contrast to 39c,d, $\mathbf{g}$, which have an ethyl or $n$-decyl group at this position. The stereoselectivity is controlled by the chiral alkyl branch, and a density-functional theory (DFT) calculation was done to explain the stereoselectivity. The authors hypothesized that the spiroketals were formed via a tandem ligand-exchange and ligandcoupling reaction (Scheme 11). The ability of these chiral spiroketals to promote asymmetric induction was demonstrated during the synthesis of (+)-biscarvacrol, ${ }^{27}$ a naturally occurring bridge-ring system (Scheme 12).

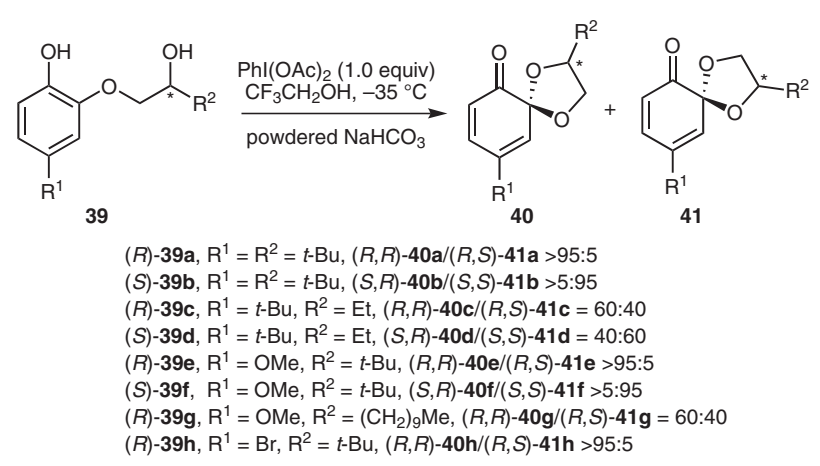

Scheme 10 Dearomatization of phenolic alcohols 39 into orthoquinone monoketals $\mathbf{4 0}$ and $\mathbf{4 1}$

Pettus and co-workers developed a diastereoselective dearomatization reaction and utilized it in the enantioselective synthesis of 4,6-dihydroxy-4-alkylcyclohexenone core structure with anticancer properties (Scheme 13). ${ }^{28}$ This transformation was presumed to involve (1) in situ generation of PhI(OTf)OTMS, (2) oxidation of the phenol ring, (3) cyclization with the amide carbonyl, and finally (4) hydrolysis of the iminium species. The other diastereomer was not observed in the ${ }^{1} \mathrm{H}$ NMR spectrum of the crude product mixture. The modified conditions used here have significantly improved the versatility of this dearomatization process compared to their previous conditions, which used iodobenzene di(trifluoroacetate) as the oxidant. ${ }^{29}$ Compound (-)-45 is the precursor of syn-diol $(-)-46$, a structure with anticancer properties.

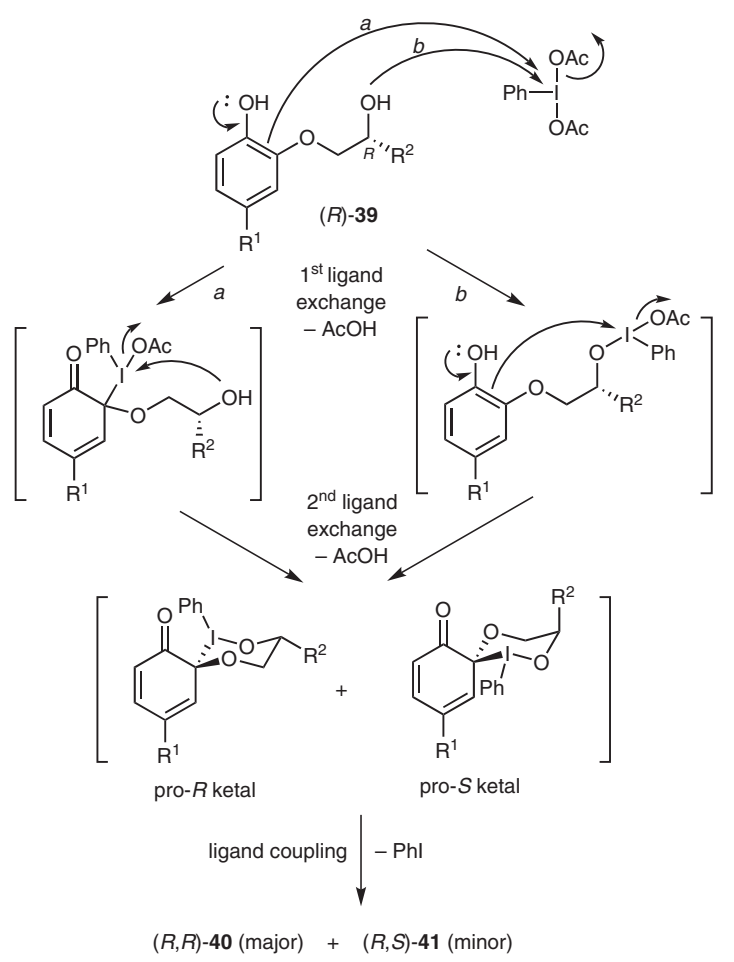

Scheme 11 Plausible mechanism of the iodobenzene diacetate mediated spiroketalization of phenolic alcohols 39 


$$
\begin{aligned}
& \underbrace{}_{(S)-39 \mathrm{i}} \\
& \downarrow \begin{array}{l}
\mathrm{TsOH} \cdot \mathrm{H}_{2} \mathrm{O} \\
\text { acetone }
\end{array} \\
& \text { (4+2] } \\
& \text { (+)-biscarvacrol } \\
& \begin{array}{l}
\text { er } 93: 7 \\
56 \%
\end{array} \\
& \text { (1) } \\
& \text { (R)-43 }
\end{aligned}
$$

Scheme 12 Enantioselective synthesis of (+)-biscarvacrol

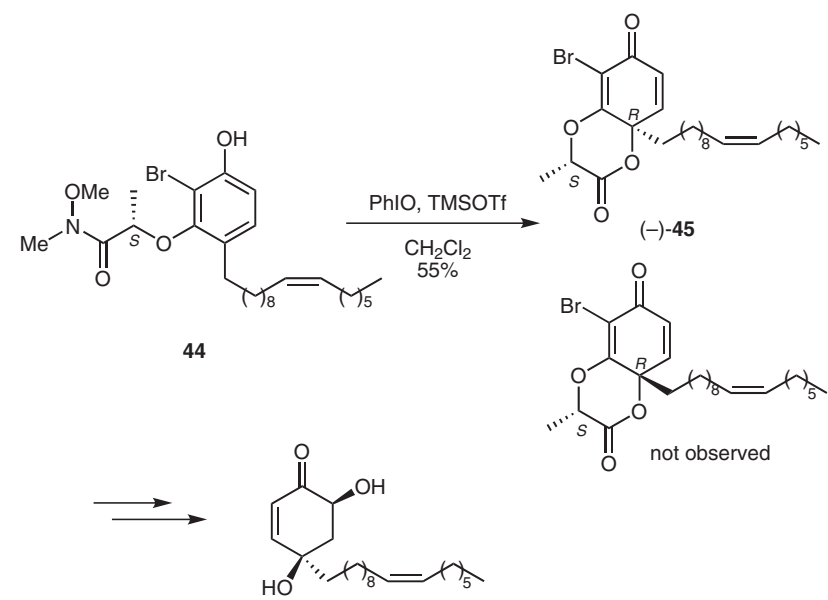

$(-)-46$

Scheme 13 Dearomatization and diastereoselective synthesis of resorcinol-derived cyclohexadienone $\mathbf{4 5}$

\subsection{Controlled by Chiral Catalyst}

Gaunt and co-workers reported a process that directly converts para-substituted phenol 47 into the highly functionalized chiral molecule 48 via oxidative dearomatization and a desymmetrizing secondary-amine-catalyzed asymmetric intramolecular Michael addition (Scheme 14). ${ }^{30}$ This one-step transformation constructs a complex structure with exquisite control of three new stereogenic centers. The corresponding decalin derivatives were formed with superb control of stereochemistry (up to $>20: 1 \mathrm{dr}$ and 99\% ee)

You and Gu developed an intramolecular aza-Michael reaction catalyzed by a cinchonine-derived thiourea
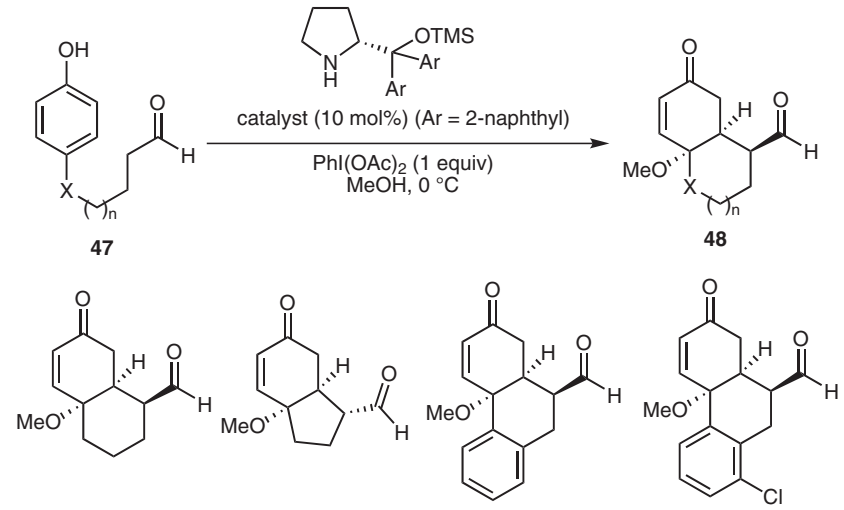

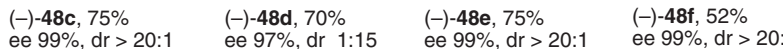

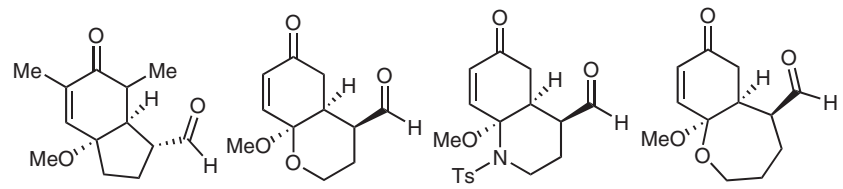

$\begin{array}{llll}(-)-\mathbf{4 8 g}, 75 \% & (-)-\mathbf{4 8 h}, \mathbf{8 4} \% & (-)-\mathbf{4 8 i}, 68 \% & (-)-\mathbf{4 8 j}, \mathbf{7 4 \%} \\ \text { ee } 40 \%, \text { dr } 2: 1 & \text { ee } 99 \%, \text { dr }>20: 1 & \text { ee } 99 \%, d r>20: 1 & \text { ee } 97 \%, \text { dr } 6.711\end{array}$

Scheme 14 Catalytic enantioselective dearomatization

(Scheme 15). ${ }^{31}$ With $5 \mathrm{~mol} \%$ of the thiourea in dichloromethane at room temperature, cyclohexadienones 50 reacted smoothly to provide compounds $\mathbf{5 1}$ in excellent yields and enantiomeric excess. With this methodology, asymmetric total synthesis of $(-)$-mesembrine ${ }^{32}$ was accomplished with high enantioselectivity ( $98 \%$ ee). The same catalyst was also used in the dearomatization of phenols 52 bearing a bis(phenylsulfonyl)methylene group (Scheme 16). ${ }^{33}$ Various highly enantioenriched polycyclic cyclohexenones 54 were prepared.

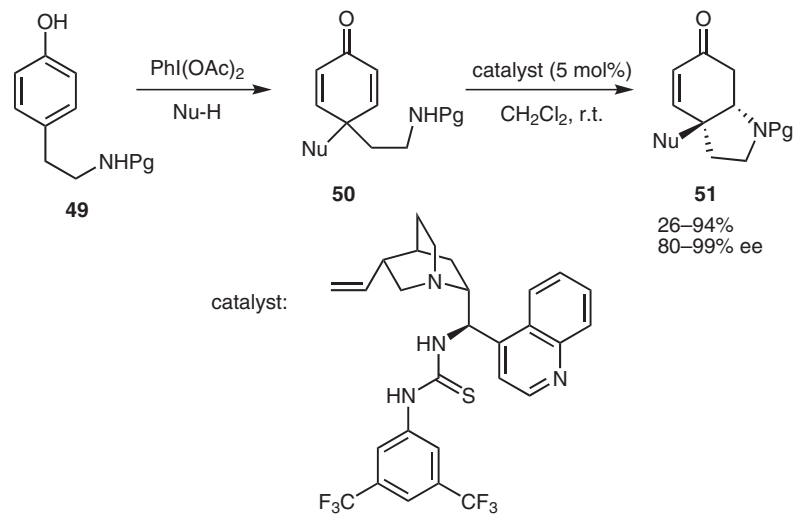

$\mathrm{Nu}=\mathrm{OH}, \mathrm{OMe}, \mathrm{OEt}, \mathrm{O}\left(\mathrm{CH}_{2}\right)_{2} \mathrm{OH}, \mathrm{O}\left(\mathrm{CH}_{2}\right)_{3} \mathrm{OH}, \mathrm{OAc}, \mathrm{NHAc}, 3,4-(\mathrm{MeO})_{2} \mathrm{C}_{6} \mathrm{H}_{3}$ $\mathrm{Pg}=\mathrm{Ts}, \mathrm{Ms}, \mathrm{Ns}$

Scheme 15 Synthesis of pyrrolidine derivatives via enantioselective intramolecular aza-Michael reaction 


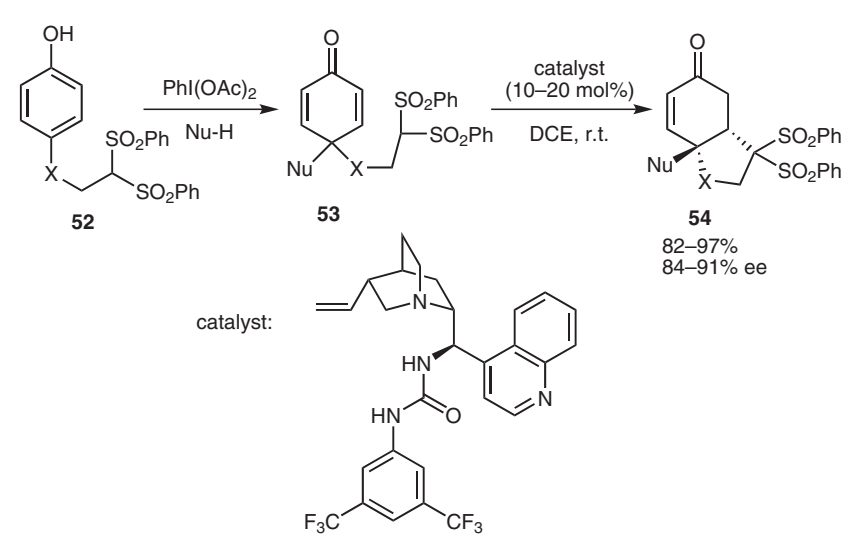

$\mathrm{Nu}=\mathrm{OH}, \mathrm{OMe}, \mathrm{OEt}, \mathrm{O}\left(\mathrm{CH}_{2}\right)_{2} \mathrm{OH}, \mathrm{O}\left(\mathrm{CH}_{2}\right)_{3} \mathrm{OH}, \mathrm{OAC}$<smiles>[X]=Cc1ccccc1C</smiles>

Scheme 16 Asymmetric intramolecular Michael reaction

In an alternative to oxidation, the enantioselective dearomatization of phenols can also proceed in another way. Recently, Hamada and colleagues reported a palladiumcatalyzed intramolecular ipso-Friedel-Crafts allylic alkylation of phenols 55 to afford spiro[4.5]cyclohexadienones 56 (Scheme 17). ${ }^{34}$ The method was thus applied to the catalytic enantioselective construction of an allcarbon quaternary spirocenter.<smiles>COC(=O)OCC(Cc1ccc(O)cc1C)(OC(C)(C)C)C(=O)OC</smiles>

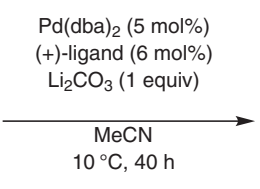

55

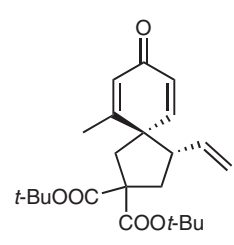

56 $89 \%$ ee (major isomer) (+)-ligand:

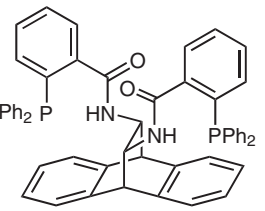

55

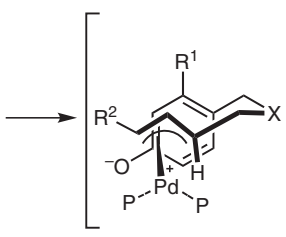<smiles>[R]c1cc(/C=C/C)cc(/C=C/C)c1OP(P)P(F)P</smiles>

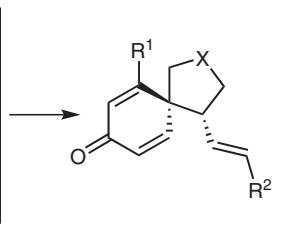

Scheme 17 Enantioselective construction of an all-carbon quaternary spirocenter

\subsection{Controlled by Chiral Hypervalent Iodine}

Asymmetric dearomatization induced by chiral hypervalent iodine reagent is still a challenge in organic synthesis. $^{35}$ In 2008, Kita and co-workers developed the symmetric chiral iodine(III) reagent $\mathbf{6 0}$ and applied it in the tandem enantioselective oxidative dearomatization and spirolactonization reaction of naphthols (Scheme 18). ${ }^{36}$ The enantiomeric excess values for the products reached $86 \%$. The reaction might proceed through an 'associative ${ }^{14,37}$ or 'dissociative ${ }^{38}$ pathway. The higher levels of asymmetric induction were observed in those reactions carried out in nonpolar and moderately polar solvents such as carbon tetrachloride, dichloromethane, and chloroform, in contrast to the polar solvents such as hexafluoroisopropanol, and with substrates carrying electron-withdrawing substituents, rather than those with electron-donating substituents. These observations support an associative mechanism. A catalytic version of the same reaction afforded inferior enantioselectivity (up to $69 \%$ ee; Scheme 19).

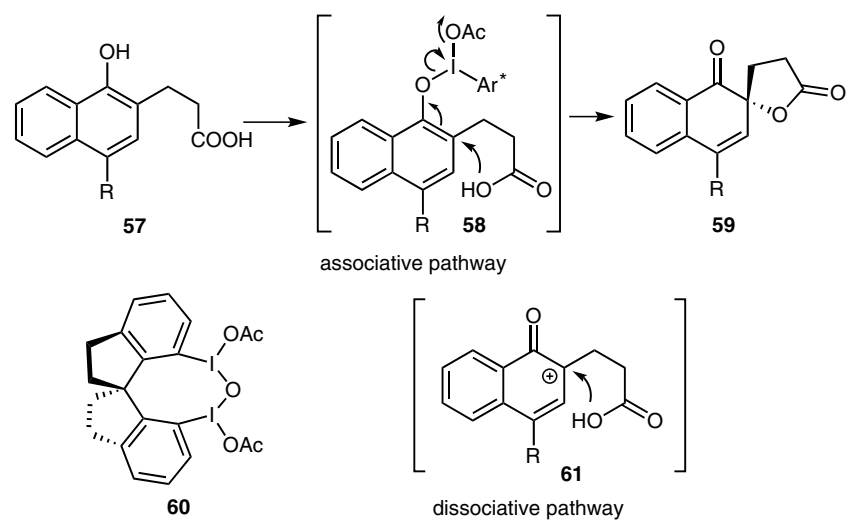

Scheme 18 Enantioselective spirolactonization and plausible reaction mechanisms

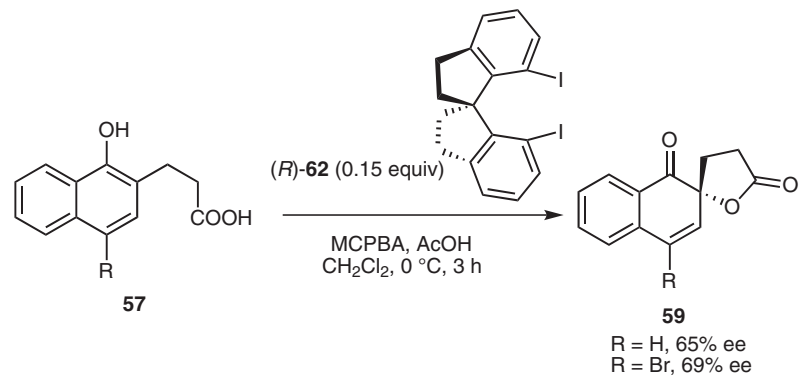

Scheme 19 Catalytic application of the chiral hypervalent iodine(III) reagent $(R)-62$

Ishihara and colleagues reported a similar spirolactonization reaction mediated by chiral iodoarenes 65 with $m$ chloroperoxybenzoic acid as co-oxidant (Scheme 20). ${ }^{39} \mathrm{In}$ the presence of $10 \mathrm{~mol} \%$ of $\mathbf{6 5}$, lactones 64 bearing an electron-donating or an electron-withdrawing group were formed in good to excellent yields (up to $92 \%$ ee). The active $\lambda^{3}$-iodane catalyst may be stabilized by the electron donation from the carbonyl groups of the lactic amides to 
the electron-deficient iodine(III) center, as in 66, or may be activated by the hydrogen bonding between the mesityl-protected NH groups and the oxygen ligands connected to the iodine atom, as in $\mathbf{6 7 .}$

In 2009, Quideau et al. developed an asymmetric iodoarene-mediated hydroxylative dearomatization reaction (Scheme 21). ${ }^{40}$ In the presence of $10-200 \mathrm{~mol} \%$ of the chiral iodoarene, the enantioselectivities of $o$-quinol 69 or epoxide 70 were up to $50 \%$ ee. Both $\lambda^{3}$ - and $\lambda^{5}$-iodanemediated mechanisms were proposed (Scheme 22).

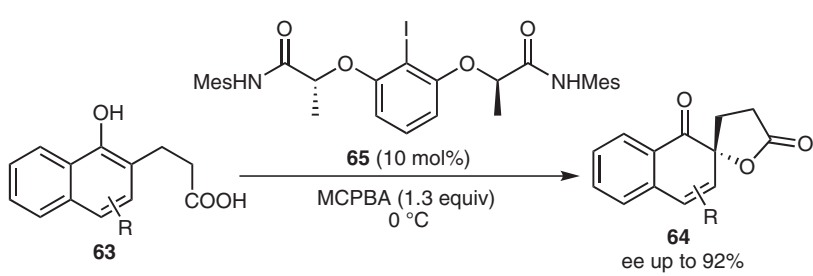

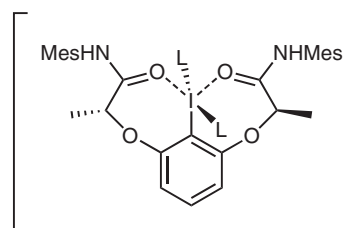

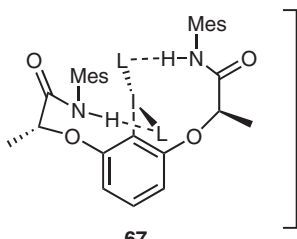

Scheme 20 Catalytic oxidative spirolactonization<smiles>Cc1ccc2ccccc2c1O</smiles>

68<smiles>[R]C(C(=O)O)c1ccccc1I</smiles>

$\mathrm{R}=\mathrm{Me}, \mathrm{Et}, n-\mathrm{Bu}, i-\mathrm{Pr}, i-\mathrm{Bu}$<smiles>COc1ccc2ccccc2c1-c1c(I)c(C(=O)O)cc2ccccc12</smiles><smiles>C[C@]1(O)C=Cc2ccccc2C1=O</smiles>

69<smiles>C[C@]1(O)C(=O)c2ccccc2C2OC21</smiles><smiles>O=C(O)c1ccc2ccccc2c1-c1c(I)ccc2ccccc12</smiles><smiles>COc1ccccc1-c1c(I)c(OC)cc(C(=O)O)c1OC</smiles>

Scheme 21 Enantioselective iodoarene-mediated hydroxylative dearomatization

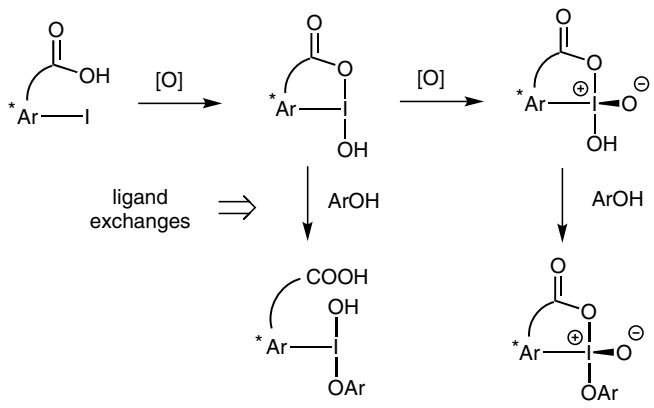

Scheme 22 Proposed mechanism of hydroxylative dearomatization
In the same year, Birman and Boppisetti developed a new class of chiral iodine $(\mathrm{V})$ derivatives such as $\mathbf{7 6}$ with a chiral oxazoline group at the ortho-position (Scheme 23). ${ }^{41}$ This kind of chiral polyvalent iodine reagent proved to be efficient in promoting the transformation of $o$-alkylphenols to $o$-quinol Diels-Alder dimers with significant asymmetric induction.

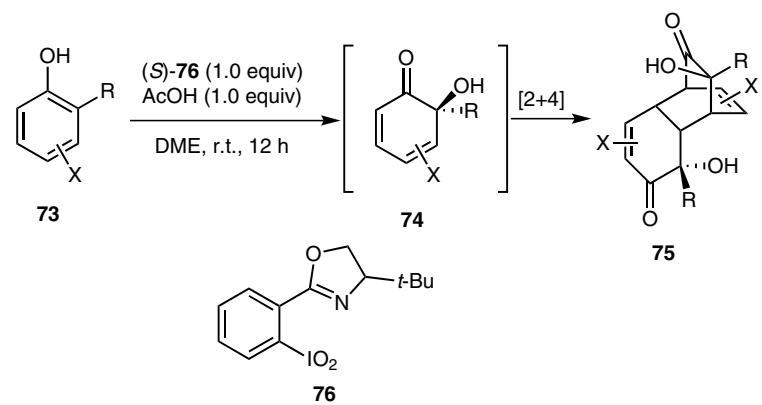

Scheme 23 Asymmetric oxidation of isomeric dimethylphenols with 76

\section{Enantioselective Phenol Dearomatization Strategies in Complex Syntheses}

\subsection{With the Formation of a Carbon-Oxygen Bond}

In the total synthesis of (-)-acutumine (81), which was originally isolated from the Asian vine Menispermum dauricum and possesses selective T-cell cytotoxicity and antiamnesic properties, the iodobenzene diacetate mediated oxidative dearomatization was used as the key step to construct masked $o$-benzoquinone derivative $\mathbf{7 8}$ (Scheme 24). ${ }^{42}$ This result highlighted the utility of iodine(III) reagents for the dearomatization of complex substrates.
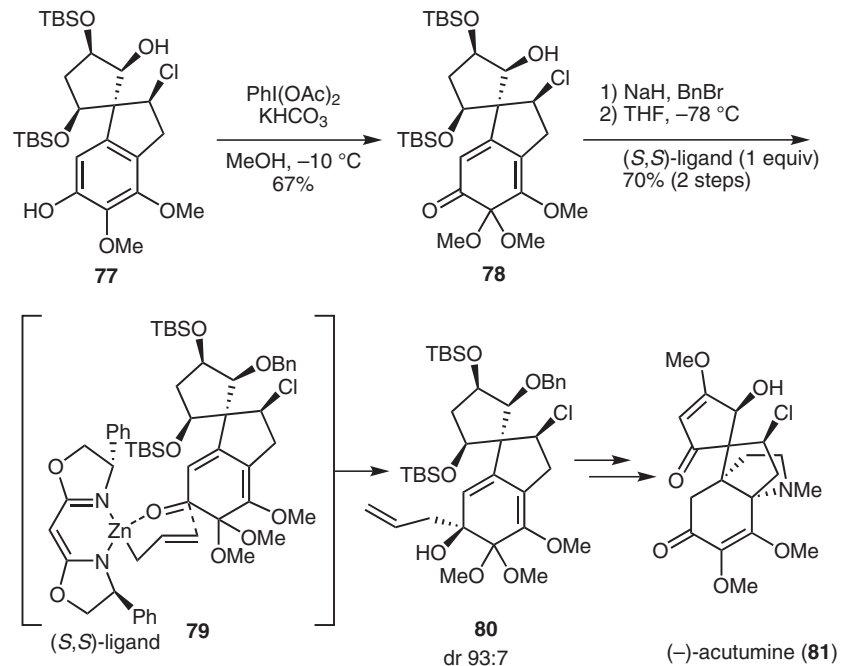

Scheme 24 Total synthesis of (-)-acutumine 
A cascade process involving a hypervalent iodine induced intramolecular oxidative dearomatization and an intramolecular dipolar cycloaddition ${ }^{43}$ was reported by Sorensen and co-workers ${ }^{44}$ for the construction of the pentacyclic core of cortistatin A (86; Scheme 25). The exposure of compound 82 to iodobenzene diacetate ${ }^{45}$ in trifluoroethanol directly produced compound $\mathbf{8 5}$ as a single diastereomer through two oxidations and two ring formations.
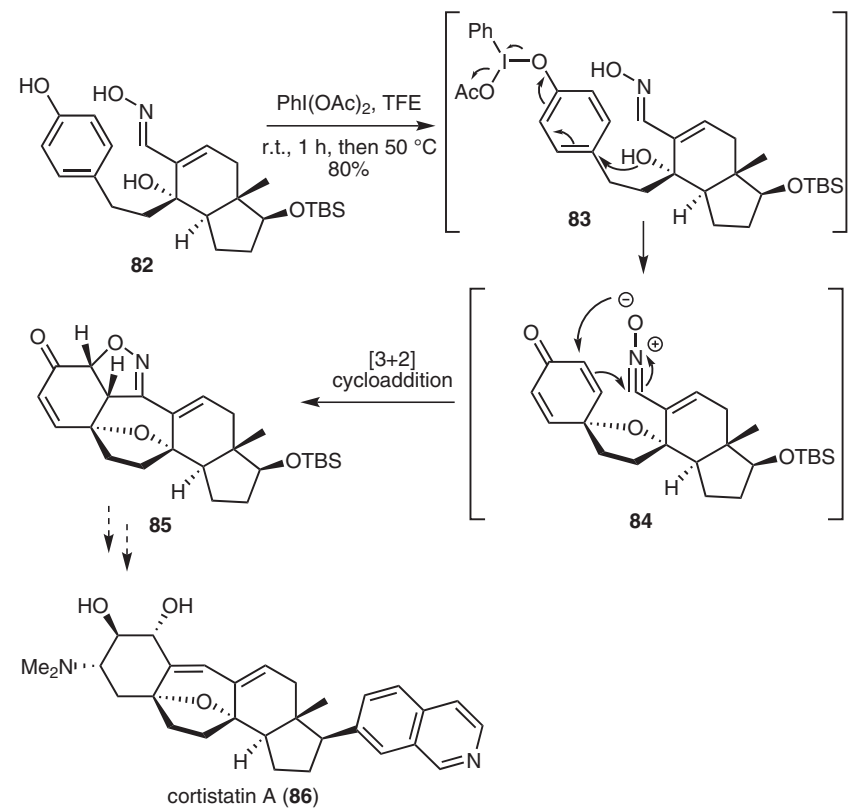

Scheme 25 Total synthesis of cortistatin A

As shown in Scheme 26, a concise asymmetric synthesis of (+)-rishirilide B (92) was reported by Pettus and coworkers. ${ }^{46}$ Resorcinol 87 was coupled with lactate derivative $\mathbf{8 8}$ through a Mitsunobu reaction and a deprotection. Diastereoselective oxidative dearomatization of $\mathbf{8 9}$ presumably proceeds via chair-like transition state $\mathbf{9 0}$ and leads to chirality transfer from the chiral auxiliary to af- ford 1,4-dioxan-2-one $\mathbf{9 1}$ in high diastereoselectivity. Further transformations of $\mathbf{9 1}$ completed an efficient asymmetric total synthesis of (+)-rishirilide B (92) in 15 steps and a $12.5 \%$ overall yield.

Recently, Pettus and colleagues also developed an oxidative dearomatization induced [5+2]-cascade reaction enabling the synthesis of $\alpha$-cedrene, $\alpha$-pipitzol, and seccedrenol (Scheme 27). ${ }^{47}$ The benzylic stereocenter effectively guides the formation of the first two stereocenters during the intramolecular [5+2] cycloaddition of the respective phenoxonium intermediate across the tethered olefin. $^{46}$

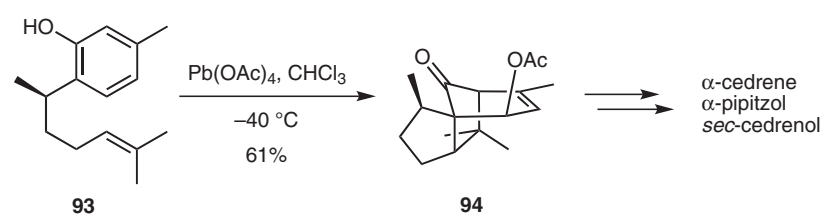

Scheme 27 Synthesis of $\alpha$-cedrene, $\alpha$-pipitzol, and sec-cedrenol

Baran and co-workers executed a sequential Barton arylation, Wessely oxidation and Diels-Alder strategy to create the core of the natural product, maoecrystal V (Scheme 28). ${ }^{48}$ A similar process was reported by Mehta and Maity in the preparation of the complete carbon framework present in tashironin-type sesquiterpenoid natural products. ${ }^{49}$

Porco and co-workers described the synthesis of (-)-mitorubrin (106) and related azaphilone natural products using copper-mediated enantioselective oxidative dearomatization of resorcinols (Scheme 29) ${ }^{50}$ Dearomatization of the resorcinol aldehyde 101 using complex 102 was achieved in a regioselective manner with high enantioselectivity to afford vinylogous acid 103. Enyne 103 was subjected to copper(I) iodide catalyzed cycloisomerization to afford the mitorubrin core structure 104 (58\% yield and 97\% ee for two steps). Further esterification with acid $\mathbf{1 0 5}$ and final deprotection afforded the desired azaphilone (-)-mito-
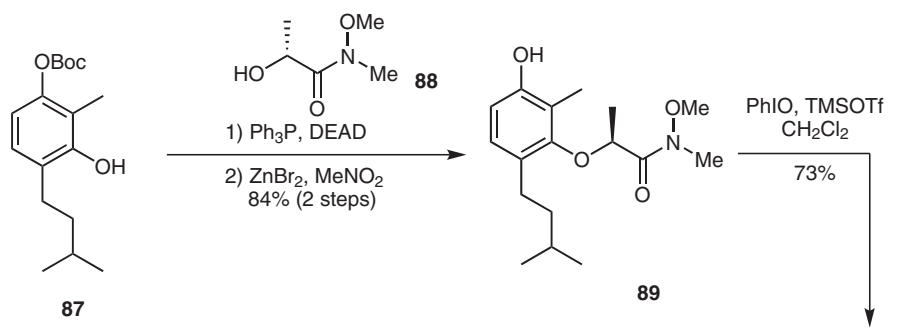

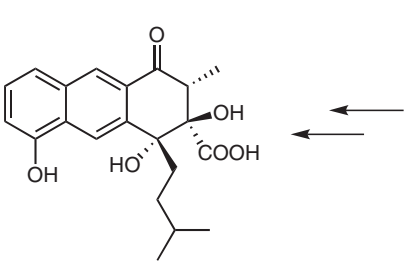

(+)-rishirilide B (92)

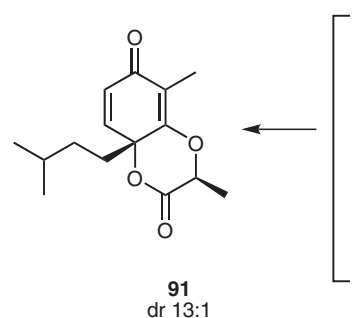

$\underset{\operatorname{91}}{913: 1}$

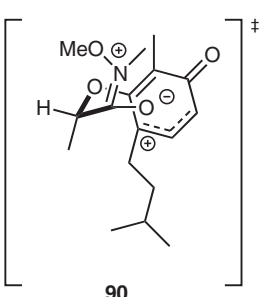

90

Scheme 26 Total synthesis of (+)-rishirilide B 
<smiles>C=CC(=O)OCC1(c2cccc(C)c2OC(=O)C=C)CCC(OC(=O)C=C)C(C)(C)C1=O</smiles>

95<smiles>C=COC(=O)OCC1(C2=C(OC)C(C)=C[C@H](OC)C2=O)CCC(OC(C)(C)C)C(C)(C)C1=O</smiles>

97<smiles>CCCCCC1CCCCC1</smiles>

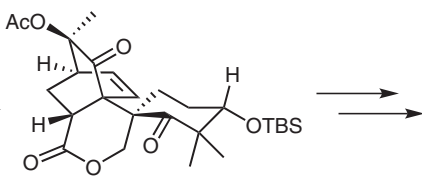

$\stackrel{98}{\text { major diastereomer }}$

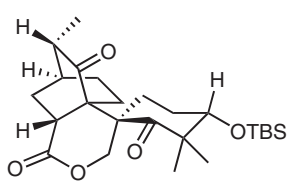

99

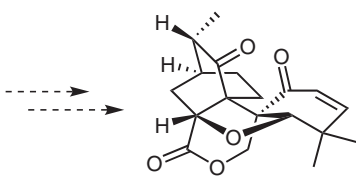

maoecrystal V (100)

Scheme 28 Total synthesis of maoecrystal V

rubrin (106). This convergent synthesis features the highly enantioselective oxidative dearomatization of resorcinol aldehyde using a readily accessible chiral bis- $\mu$ oxodicopper complex.

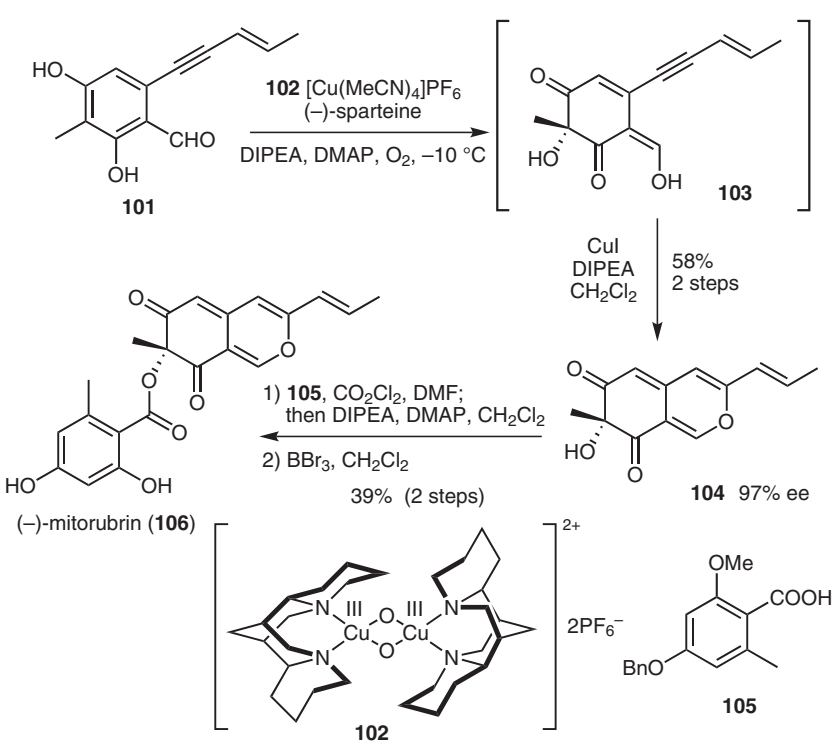

Scheme 29 Total synthesis of (-)-mitorubrin

This oxidation system was also used in the enantioselective synthesis of $(+)$-chamaecypanone $\mathrm{C}$, a novel microtubule inhibitor (Scheme 30). ${ }^{51}$ In the presence of copper bis(oxo) complex derived from (-)-sparteine, the chemoselective ortho-dearomatization of 2,4-disubstituted lithium phenolate led to $o$-quinol 108 which equilibrated by means of a [1,2]-ketol shift to isomer 109. The latter underwent a Diels-Alder dimerization to generate bicyc-

lo[2.2.2] octenone $\mathbf{1 1 0}$ ( $>99 \%$ ee). After a retro-DielsAlder reaction and a subsequent Diels-Alder cycloaddition with the in situ generated diarylcyclopentadienone, the desired enantiopure cycloadduct 113 was obtained in $61 \%$ yield.
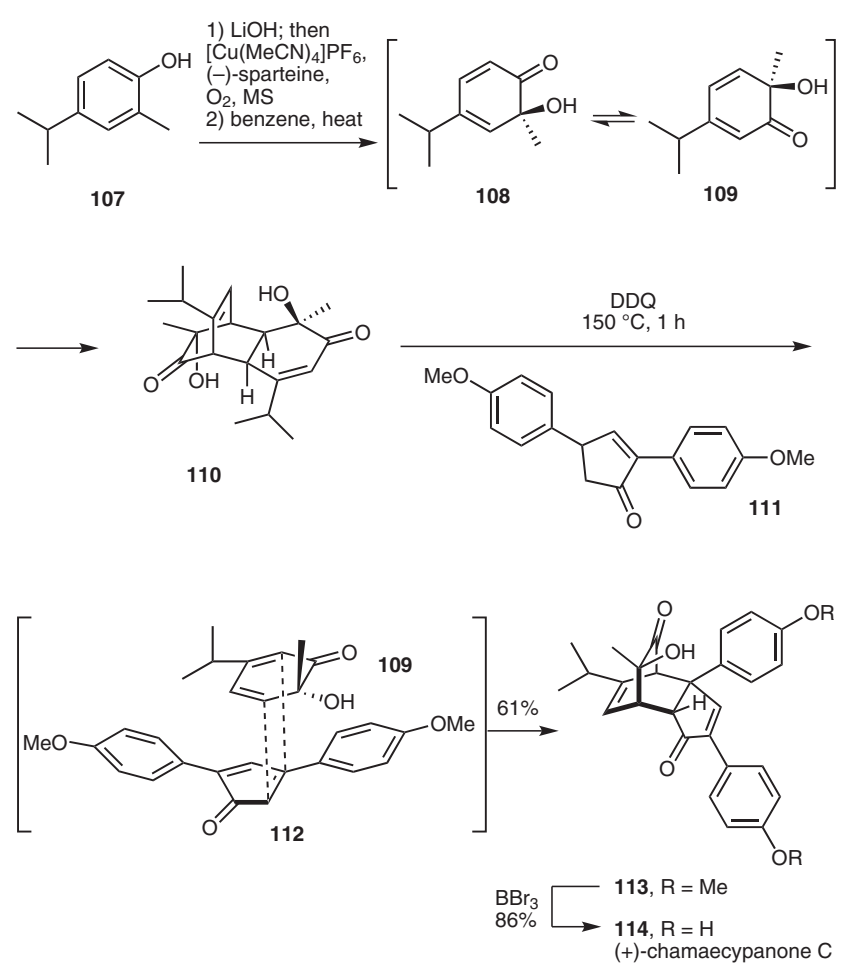

Scheme 30 Total synthesis of (+)-chamaecypanone C

Dimethylketal 116, generated from the corresponding oxidative dearomatization of $o$-prenylphenol 115, underwent a transketalization with $(2 S, 4 S)$-pentanediol to form chiral quinone monoketal 117. The latter is a key intermediate in the total synthesis of $\mathbf{1 1 8}$, the epoxyquinoid natural product (-)-jesterone (Scheme 31). ${ }^{52}$

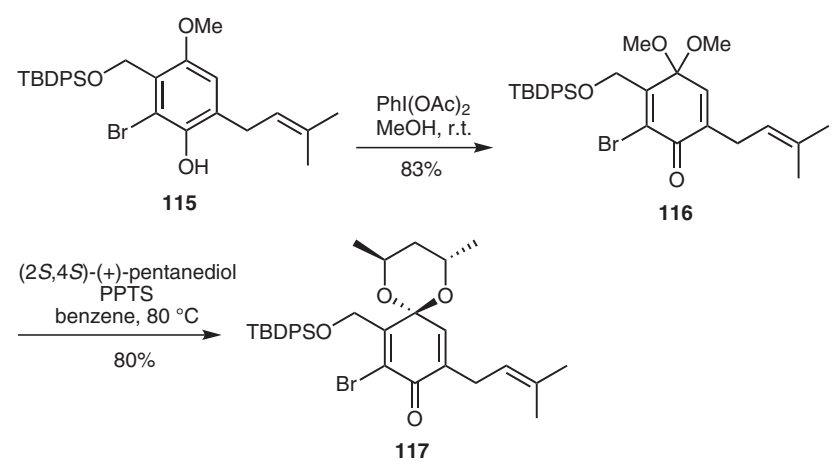

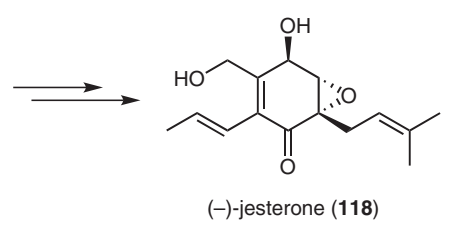

Scheme 31 Total synthesis of (-)-jesterone 


\subsection{With the Formation of a Carbon-Carbon Bond}

As highlighted in the previous section, many oxidative dearomatizations involve soft carbon nucleophiles. The carbon-carbon bond formation during the oxidative dearomatization is of significant interest in complex natural product synthesis. Kita and co-workers reported the first versatile iodoarene-catalyzed carbon-carbon bondforming reaction (Scheme 32 ).$^{53}$ With the in situ generated active catalytic iodine(III) species, the oxidative dearomatization of compound $\mathbf{1 1 9}$ produced the discrete carbocation intermediate 120, which was selectively trapped by the pendant aromatic ring to afford the desired spirocyclic amino ester 121. This reaction was used in the key synthetic process of producing biologically important amaryllidaceae alkaloids, such as (+)-maritidine (123).

An important example of the oxidative dearomatization of a phenolic substrate with concomitant carbon-carbon bond formation in the context of complex total synthesis was reported by Nicolaou and colleagues in their enantioselective synthesis of (-)-platensimycin (Scheme 33). ${ }^{54}$ The authors employed oxidative dearomatization with an intramolecular para-spiroannulation of a pendant allylsilane ${ }^{13,14,37 e, 55}$ using hypervalent iodine activation to assemble the first two rings of the natural product. Activation of the free phenol moiety by iodobenzene diacetate in a polar solvent (trifluoroethanol) afforded the activated intermediate 125 bearing a delocalized carbocation which reacted internally with the allylsilane to furnish the desired spirocyclic dienone. Subsequent removal of the ethylene acetal group led to the free aldehyde substrate 126, which was ready to undergo a radical-mediated cyclization and an acid-mediated etherification to efficiently produce the tetracyclic core of platensimycin (129). Danishefsky and Dai developed an alkylative para-dearomatization of compound $\mathbf{1 3 0}$ to synthesize 131, the core matrix of the steroidal alkaloid cortistatin A (Scheme 34). ${ }^{56}$

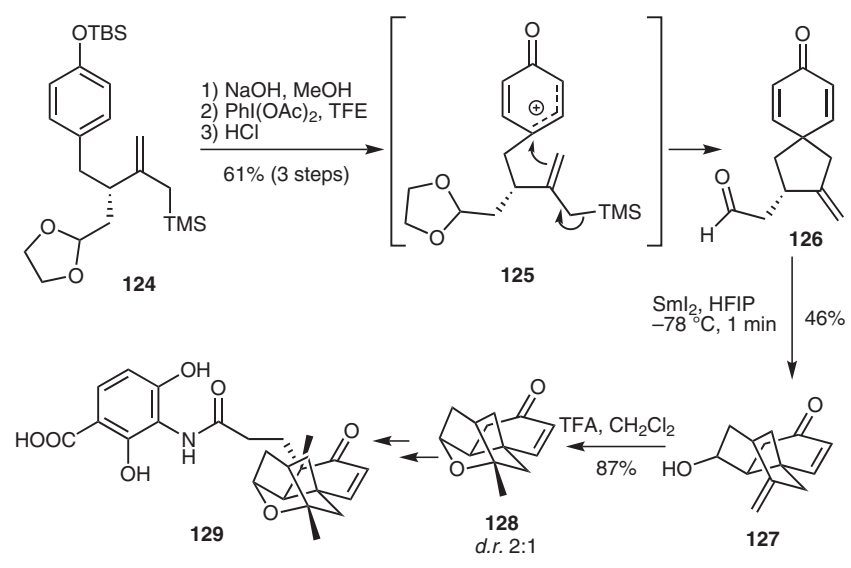

Scheme 33 Total synthesis of (-)-platensimycin

Porco and Wang made efforts toward the synthesis of the soybean lipoxygenase inhibitors, tetrapetalones A to D (Scheme 35). ${ }^{57}$ Treatment of macrocyclic hydroquinone 132 with iodobenzene diacetate led to a diastereoselective transannular $[4+3]$ cyclization and formed the tetracyclic core of the targeted molecules. The attack of the electronrich diene unit at the oxidatively activated hydroquinone moiety generated an intermediate with an allylic cation, which could rotate to form a suitable conformation (134) for reaction with the amide nitrogen atom. The paraquinolic tetracycle 135 was obtained in $42 \%$ yield from 132 via this one-pot process.

In the first total synthesis of the amaryllidaceae alkaloid (+)-plicamine (139), Ley and co-workers used a solidsupported iodobenzene diacetate (PS-DIB) to mediate the spirocyclization of $\mathbf{1 3 6}$ (Scheme 36). ${ }^{58}$ The resulting advanced intermediate $\mathbf{1 3 8}$ was also exploited for the synthesis of both (-)-obliquine (141) and (+)-plicane (142) via the common secondary amine precursor $140 .{ }^{59}$

An iron(III)-mediated cascade oxidative dearomatization and intramolecular Diels-Alder reaction was developed
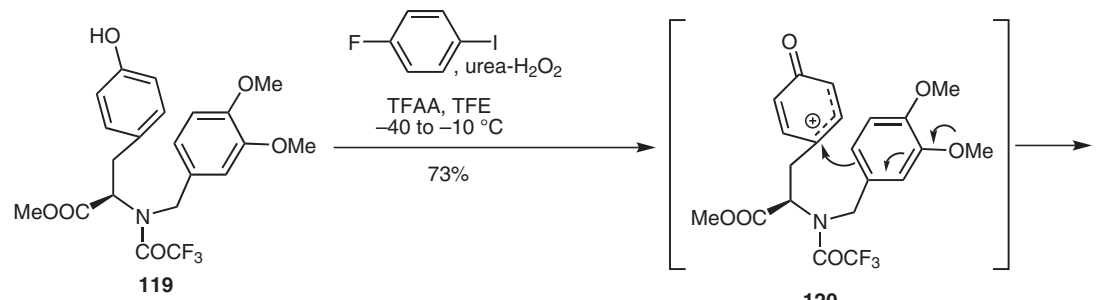

120
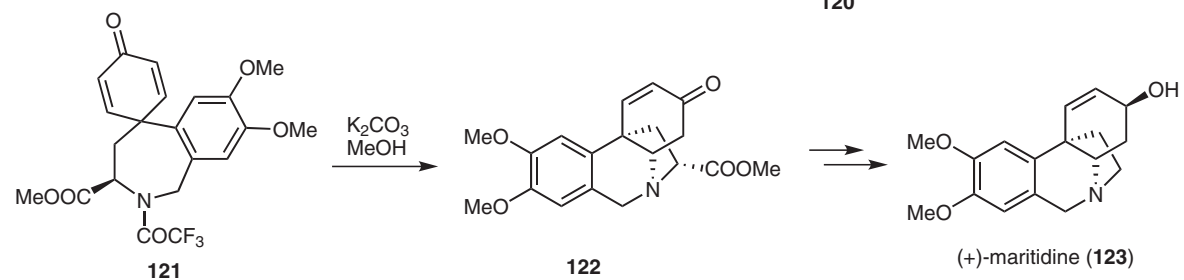

Scheme 32 Total synthesis of (+)-maritidine 


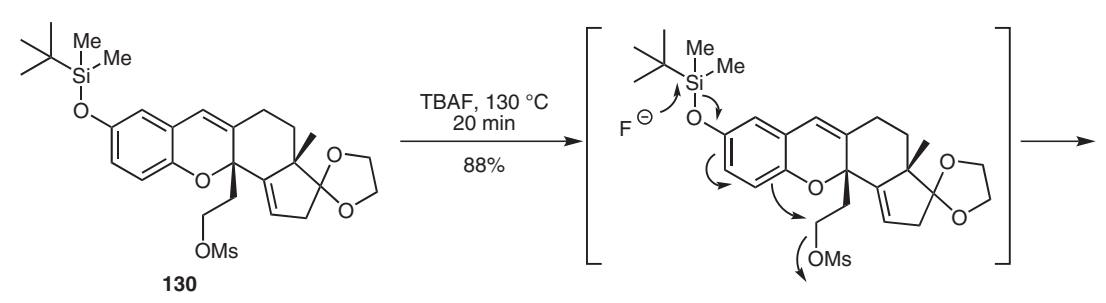

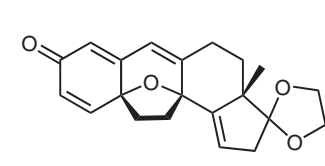

131

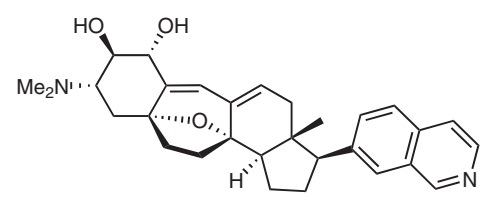

cortistatin A (86)

Scheme 34 Total synthesis of cortistatin

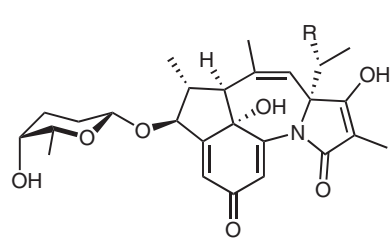

$\mathrm{R}=\mathrm{H}$, tetrapentalone $\mathrm{A}$ $R=$ OAc, tetrapentalone $B$

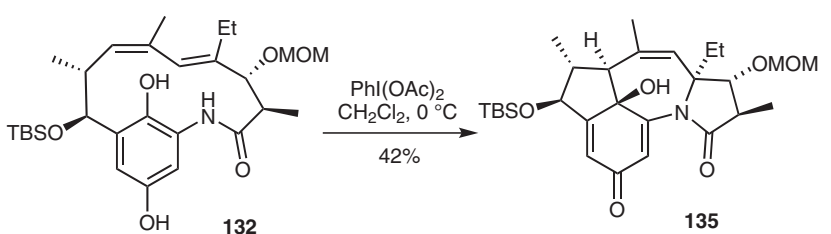
$\mathrm{Phl}(\mathrm{OAc})_{2}$

TBS

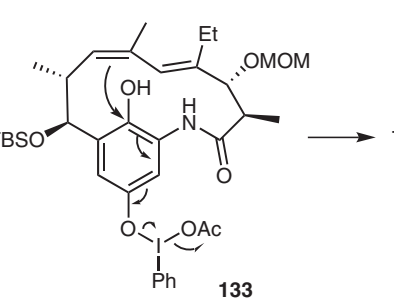

$\mathrm{R}=\mathrm{H}$, tetrapentalone $\mathrm{C}$ $\mathrm{R}=\mathrm{OAc}$, tetrapentalone $\mathrm{D}$

135
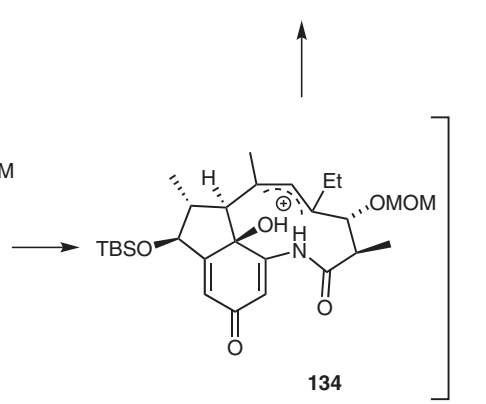

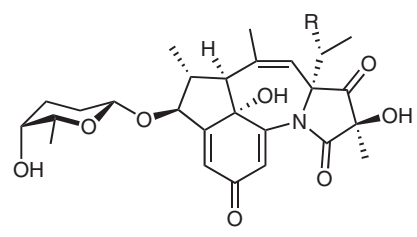

Scheme 35 Synthesis of tetrapetalones A to D

by Mulzer and Heckrodt in their total synthesis of (+)-elisabethin A (Scheme 37). ${ }^{60}$ Tricyclic compound 146 was formed via endo transition state $\mathbf{1 4 5}$. This cascade process relied on the $Z$-configuration of the terminal olefin to induce the desired stereochemistry. The facial selectivity of the diene-quinone cycloaddition is presumably dictated by the minimization of allylic strain between the substituents at $\mathrm{C} 9$ and the quinone carbonyl moiety in endo transition state 145 such that cycloadduct 146 is produced as a single diastereoisomer. The required chemoselective re-<smiles>CC(=O)N(Cc1ccc2c(c1)OCO2)C(C(=O)N(C)C)c1ccc(O)cc1</smiles><smiles></smiles><smiles>CO[C@H]1C=C[C@@]2(C(=O)N(CCc3ccc(O)cc3)C(=O)c3cc4c(cc32)CC(C)C4C)N(C)C1=O</smiles>

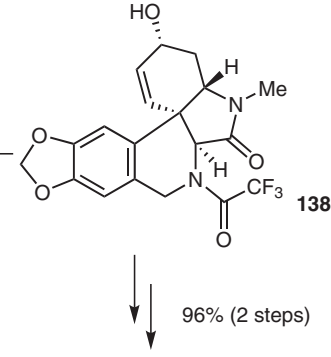

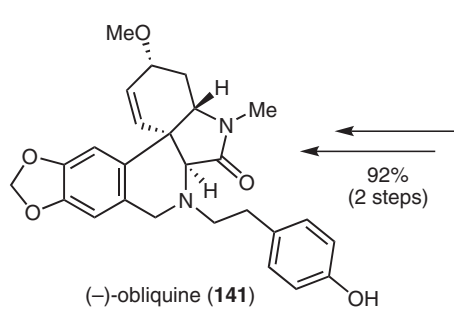<smiles>CO[C@H]1C=C[C@@]2(NNCc3cc4c(cc32)OCO4)[C@H](C)C[C@H]1CO</smiles><smiles></smiles>

(+)-plicane (142)

Scheme 36 Polymer-supported approach to the total synthesis of amaryllidaceae alkaloids

moval of the endocyclic alkene, epimerization at $\mathrm{C} 2$, and deprotection afforded (+)-elisabethin A (147). 

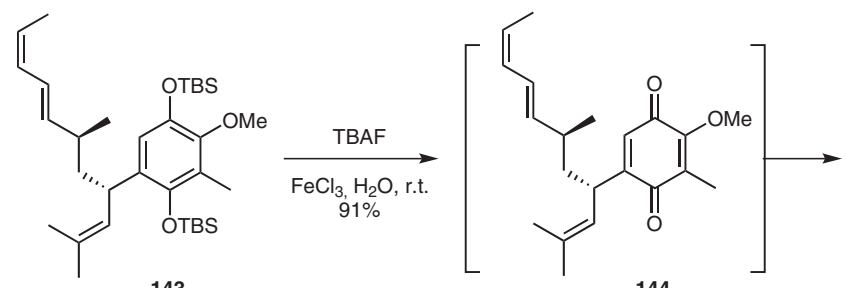

143

144
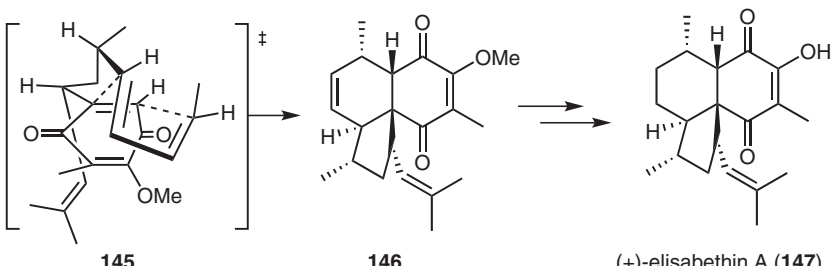

(+)-elisabethin A (147)

Scheme 37 Total synthesis of (+)-elisabethin A

In the total synthesis of the antimitotic natural product (-)-diazonamide A (154), Harran and co-workers subjected the advanced phenolic-indolic amide intermediate 148 to reaction with iodobenzene diacetate in the presence of lithium acetate in trifluoroethanol at $-20^{\circ} \mathrm{C}$ (Scheme 38). ${ }^{61}$ This treatment led to the formation of an undesired dearomatized and spiroannulated cyclohexa-2,5-dienone product $\mathbf{1 5 0}$ in $15 \%$ yield (path a). Nevertheless, the two diastereomeric macrolactams 152 and 153 were fortunately also obtained in a 1:3 ratio (ca. $30 \%$ yield) according to the proposed path $b$, through which the transient intermediate 149 is trapped intramolecularly by the nucleophilic indolic moiety, followed by rearomatization of the resulting cyclohexa-2,4-dienone intermediate $\mathbf{1 5 1}$ with a concerted oxocyclization onto its iminium unit leading to the observed benzofurans. Finally, the major benzofuran product 153 was further transformed to afford (-)-diazonamide A (154) after 14 additional steps.

\subsection{With the Formation of a Carbon-Nitrogen Bond}

Matsumoto and co-workers ${ }^{62}$ relied on 6,6-dimethoxycyclohexa-2,4-dienone derivatives as key intermediates in the synthesis of the erythrinan skeleton, an indolo[7a,1$\alpha$ ]isoquinoline core common to alkaloids isolated from many plant species of the Erythrina family. These unique tetracyclic amino structures were shown to exhibit curarelike, sedative, hypotensive and central-nervous-systemdepressant activities. The atropisomerically pure biphenylic phenol 155 was successfully dearomatized into the desired $o$-quinone monoketal 156 upon treatment with iodobenzene diacetate in methanol at room temperature (Scheme 39). ${ }^{62}$ Subsequent Lewis acid promoted aza-spirocyclization converted compound 156 into 157 . Both cyclohexa-2,4-dienone and the spiro-isoquinoline product proved to be enantiomerically pure, thus demonstrating the efficacious transmission of the axial chirality of the biphenyl 155 to the $\mathrm{sp}^{3}$-center chirality of the spirocycle $\mathbf{1 5 7}$ during this focal $\mathrm{S}_{\mathrm{N}} 2^{\prime}$-type reaction of the synthesis. ${ }^{62 \mathrm{a}}$ The total synthesis of $(+)-O$-methylerysodienone (158)

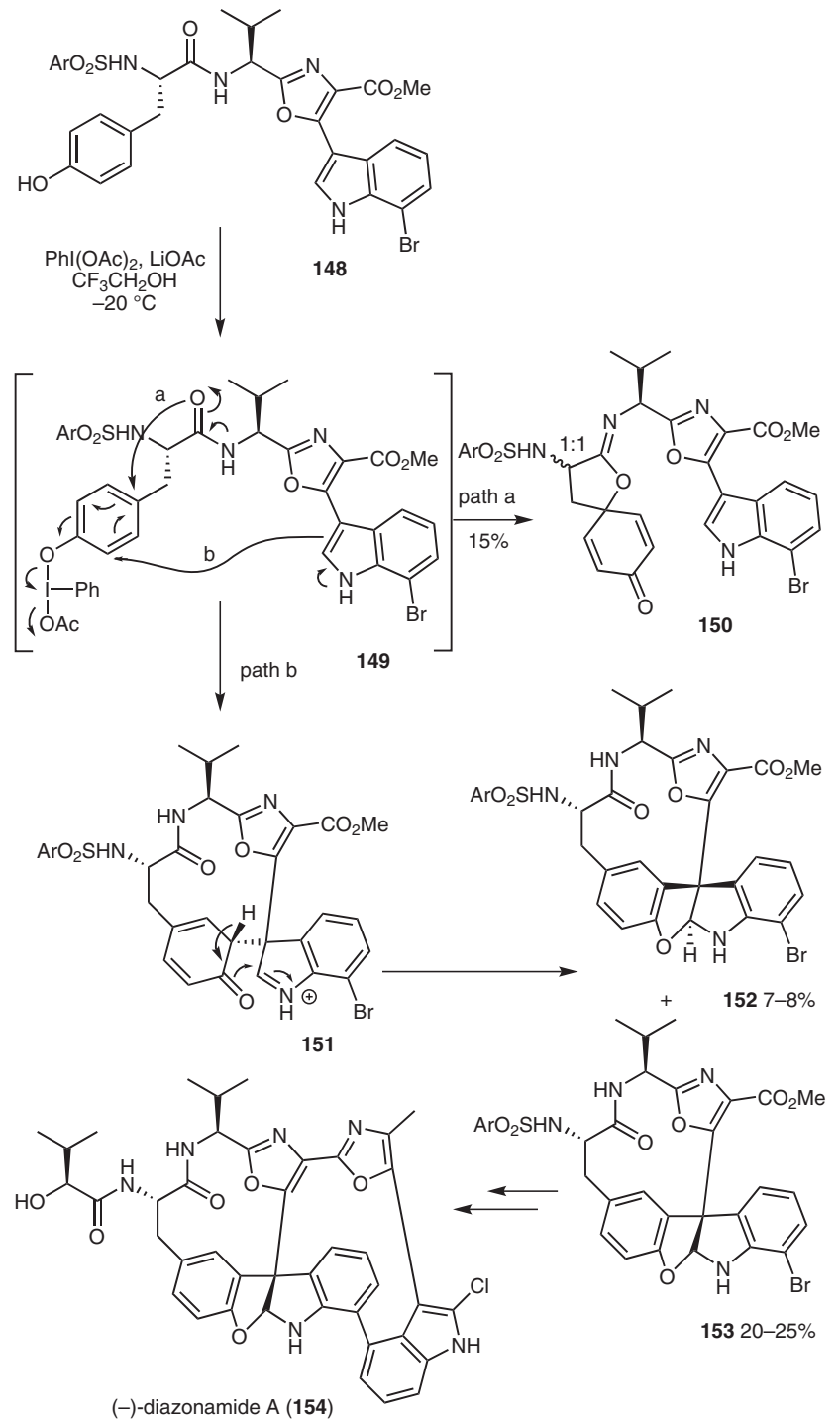

Scheme 38 Total synthesis of (-)-diazonamide A

was next completed through three additional steps. ${ }^{62 b}$ More recently, this strategy was followed by the same research group to achieve the total synthesis of (+)-11-hydroxyerythratidine (162), a C-11 oxygenated erythrinan alkaloid (Scheme 40). ${ }^{63}$

Ciufolini and co-workers reported a synthesis of the cyclohexa-2,5-dienone spirolactam 164 by treating the L-tyrosine-derived oxazoline 163 with iodobenzene diacetate in trifluoroethanol, following immediately with an acetylation (Scheme 41). ${ }^{64}$ This spirolactam then served as a common intermediate for the synthesis of $(+)$-FR901483 $(\mathbf{1 6 5})^{8 \mathrm{a}, 65}$ and (+)-TAN1251C (166). ${ }^{61}$ Further investigations led them to work with phenolic sulfonamides that turned out to be much better substrates than oxazolines for aza-spirocyclization. ${ }^{66}$ For example, sulfonamide 167 was converted into the cyclohexa-2,5-dienone spirocycle $\mathbf{1 6 8}$, which is the key synthetic intermediate for the total synthesis of the ascidian Clavelina cylindrica metabolite (-)cylindricine C (169) (Scheme 42). ${ }^{67}$ 

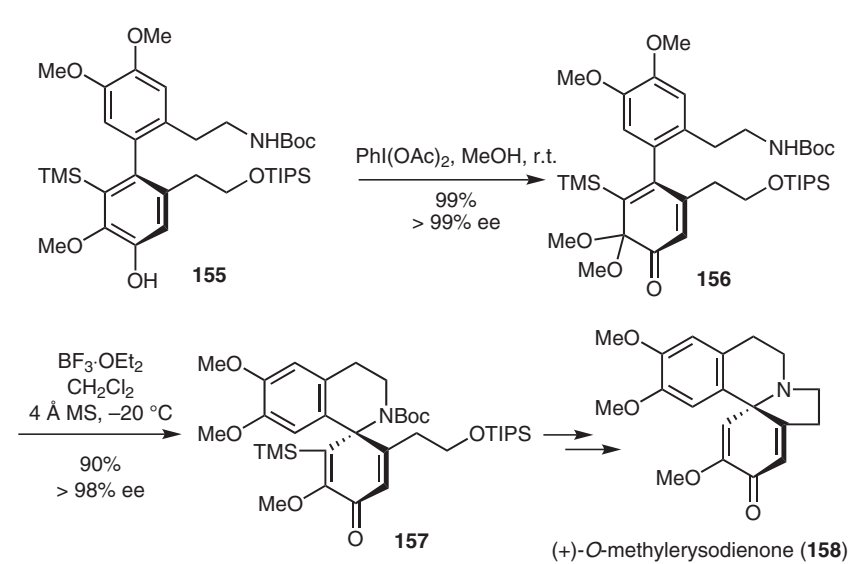

Scheme 39 Total synthesis of (+)-O-methylerysodienone
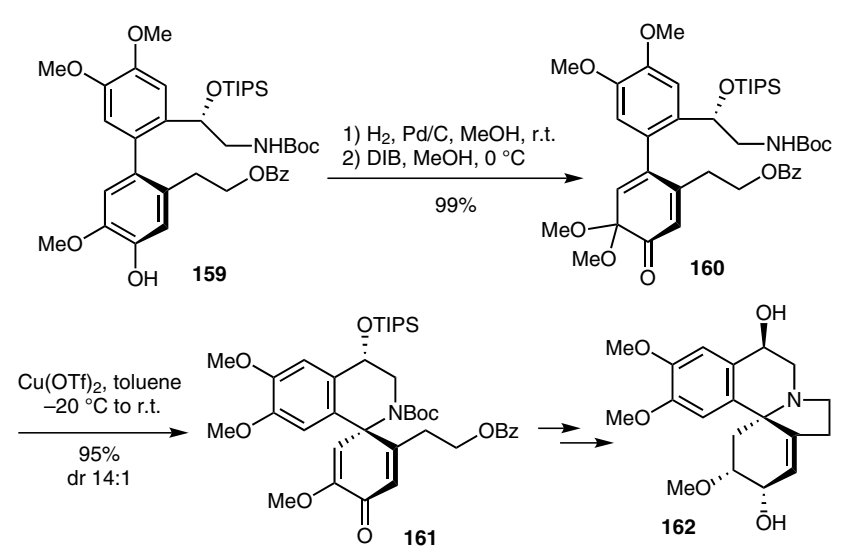

Scheme 40 Total synthesis of (+)-11-hydroxyerythratidine

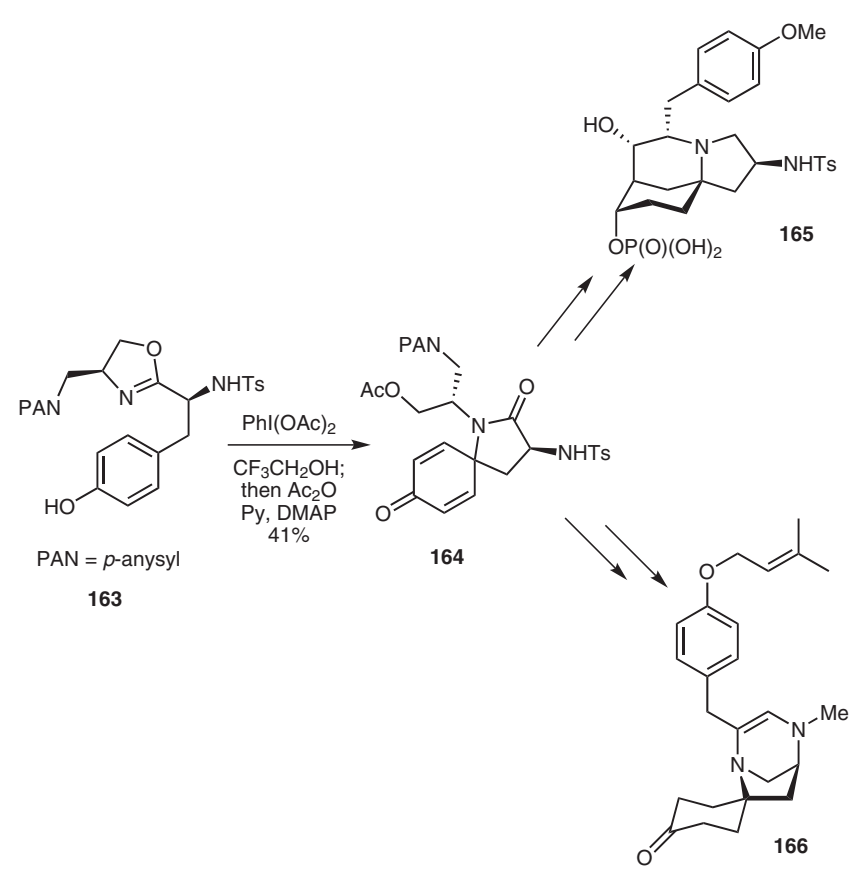

Scheme 41 Synthesis of (+)-FR901483 (165) and (+)-TAN1251C (166)

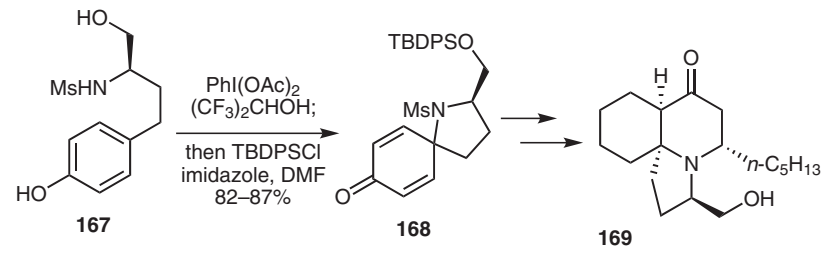

Scheme 42 Synthesis of (-)-cylindricine C (169)

Sorensen and co-workers also accomplished an enantiospecific synthesis of the potent immunosuppressant (+)FR901483 (165) by relying on a $\lambda^{3}$-iodane-mediated oxidative phenol dearomatization reaction to cast the azaspirane system (Scheme 43). ${ }^{68}$ In this case, phenolic secondary amine $\mathbf{1 7 0}$ was used as substrate to afford azaspiro[4.5]decadienone 171. Eight additional transformations completed the synthesis of the targeted (+)FR901483 (165).

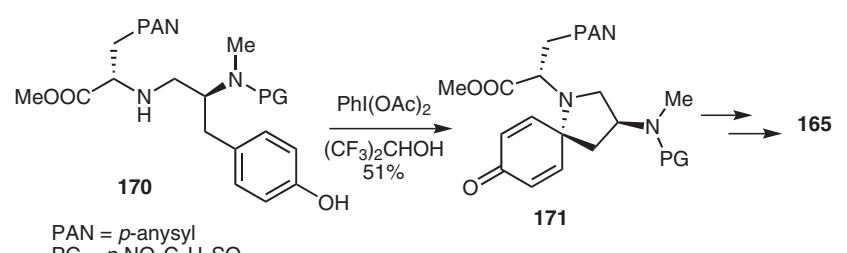

$\mathrm{PAN}=p$-anysyl
$\mathrm{PG}=p-\mathrm{NO}_{2} \mathrm{C}_{6} \mathrm{H}_{4} \mathrm{SO}_{2}$

Scheme 43 Synthesis of (+)-FR901483 (165)

A similar strategy was used by Honda and colleagues as the key step in the synthesis of (-)-TAN1251A (175), isolated from a culture of Penicillium thomii RA-89 (Scheme 44). ${ }^{69}$

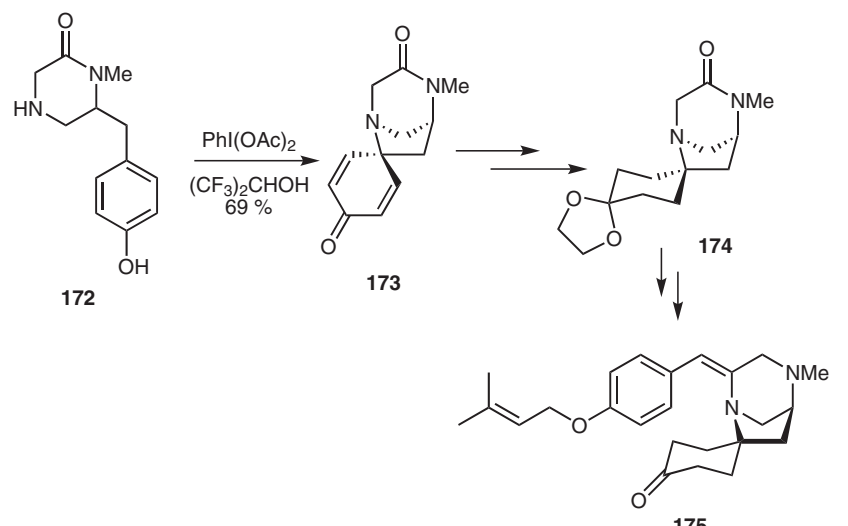

Scheme 44 Synthesis of (-)-TAN1251A (175)

\section{$5 \quad$ Conclusions}

A large number of papers have been published since the beginning of the century on the investigation of phenol dearomatizations, both in natural product synthesis and methodology development. This review highlights some recent advances in the phenol dearomatization reactions, especially those carried out in an enantioselective manner, and the application of dearomatization strategies in com- 
plex syntheses. Future research in this area should lead to additional strategies and methods for the use of new and efficient chiral reagents and catalysts which should be of great value to the field of natural products total synthesis.

\section{Acknowledgment}

Financial supports from National Natural Science Foundation of China (21072033), and the Open Project Program of Key Laboratory of Functional Small Organic Molecules, Ministry of Education, Jiangxi Normal University (No. KLFS-KF-201201) is gratefully acknowledged.

\section{References}

(1) (a) Wender, P. A.; Handy, S. T.; Wright, D. L. Chem. Ind. 1997, 765, 767. (b) Gaich, T.; Baran, P. S. J. Org. Chem. 2010, $75,4657$.

(2) (a) Bach, T. Angew. Chem. Int. Ed. 1996, 35, 729. (b) Quideau, S.; Pouységu, L. Org. Prep. Proced. Int. 1999, 31, 617. (c) Pape, A. R.; Kaliappan, K. P.; Kündig, E. P. Chem. Rev. 2000, 100, 2917. (d) Magdziak, D.; Meek, S. J.; Pettus, T. R. R. Chem. Rev. 2004, 104, 1383. (e) Keane, J. M.; Harman, W. D. Organometallics 2005, 24, 1786. (f) López Ortiz, F.; Iglesias, M. J.; Fernández, I.; Andújar Sánchez, C. M.; Gómez, G. R. Chem. Rev. 2007, 107, 1580. (g) Quideau, S.; Pouységu, L.; Deffieux, D. Synlett 2008, 467. (h) Pouységu, L.; Deffieux, D.; Quideau, S. Tetrahedron 2010, 66, 2235. (i) Roche, S. P.; Porco, J. A. Jr Angew. Chem. Int. Ed. 2011, 50, 4068.

(3) Pelter, A.; Elgendy, S. M. A. J. Chem. Soc., Perkin Trans. 1 $1993,1891$.

(4) (a) McKillop, A.; McLaren, L.; Taylor, R. J. K. J. Chem. Soc., Perkin Trans. 1 1994, 2047. (b) Felpin, F-X. Tetrahedron Lett. 2007, 48, 409.

(5) (a) Pouységu, L.; Chassaing, S.; Dejugnac, D.; Lamidey, A.M.; Miqueu, K.; Sotiropoulos, J.-M.; Quideau, S. Angew. Chem. Int. Ed. 2008, 47, 3552. (b) Mitchell, A. S.; Russell, R. A. Tetrahedron Lett. 1993, 34, 545. (c) Lion, C. J.; Vasselin, D. A.; Schwalbe, C. H.; Matthews, C. S.; Stevens, M. F. G.; Westwell, A. D. Org. Biomol. Chem. 2005, 3, 3996. (d) Quideau, S.; Pouysegu, L.; Deffieux, D.; Ozanne, A.; Gagnepain, J.; Fabre, I.; Oxoby, M. ARKIVOC 2003, (vi), 106.

(6) Karam, O.; Martin, A.; Jouannetaud, M.-P.; Jacquesy, J.-C. Tetrahedron Lett. 1999, 40, 4183.

(7) (a) Wipf, P.; Kim, Y.; Fritch, P. C. J. Org. Chem. 1993, 58, 7195. (b) Quideau, S.; Looney, M. A.; Pouységu, L.; Ham, S.; Birney, D. M. Tetrahedron Lett. 1999, 40, 615.

(8) (a) Kita, Y.; Tohma, H.; Kikuchi, K.; Inagaki, M.; Yakura, T. J. Org. Chem. 1991, 56, 435. (b) Liang, H.; Ciufolini, M. A. Chem.-Eur. J. 2010, 16, 13262.

(9) Murakata, M.; Yamada, K.; Hoshino, O. Chem. Commun. 1994, 443.

(10) (a) Kita, Y.; Tohma, H.; Inagaki, M.; Hatanaka, K.; Yakura, T. J. Am. Chem. Soc. 1992, 114, 2175. (b) Berard, D.; Giroux, M.-A.; Racicot, L.; Sabot, C.; Canesi, S. Tetrahedron 2008, 64, 7537.

(11) Guérard, K. C.; Chapelle, C.; Giroux, M.-A.; Sabot, C.; Beaulieu, M.-A.; Achache, N.; Canesi, S. Org. Lett. 2009, $11,4756$.

(12) Guérard, K. C.; Sabot, C.; Beaulieu, M.-A.; Giroux, M.-A.; Canesi, S. Tetrahedron 2010, 66, 5893.

(13) Sabot, C.; Commare, B.; Duceppe, M. A.; Nahi, S.; Guérard, K. C.; Canesi, S. Synlett 2008, 3226.
(14) Quideau, S.; Looney, M. A.; Pouységu, L. Org. Lett. 1999, $1,1651$.

(15) Desjardins, S.; Andrez, J.-C.; Canesi, S. Org. Lett. 2011, 13, 3406.

(16) Gloer, J. B.; Rinderknecht, B. L.; Wicklow, D. T.; Dowd, P. F. J. Org. Chem. 1989, 54, 2530.

(17) Puri, A.; Saxena, R.; Saxena, R. P.; Saxena, K. C.; Srivastava, V.; Tandon, J. S. J. Nat. Prod. 1993, 56, 995.

(18) Nicolaou, K. C.; Roecker, A. J.; Follmann, M.; Baati, R. Angew. Chem. Int. Ed. 2002, 41, 2107.

(19) Jacquemot, G.; Canesi, S. J. Org. Chem. 2012, 77, 7588.

(20) Dohi, T.; Nakae, T.; Ishikado, Y.; Kato, D.; Kita, Y. Org. Biomol. Chem. 2011, 9, 6899.

(21) Reactions of alkenyliodonium salts with nucleophiles: (a) Ochiai, M.; Sumi, K.; Takaoka, Y.; Kunishima, M.; Nagao, Y.; Shiro, M.; Fujita, E. Tetrahedron 1988, 44, 4095. (b) Chen, J.-M.; Huang, X. Synlett 2004, 552. (c) Yan, J.; Jin, H.; Chen, Z. J. Chem. Res. 2007, 233.

(22) Liang, J.; Chen, J.; Du, F.; Zeng, X.; Li, L.; Zhang, H. Org. Lett. 2009, 11, 2820.

(23) Matsuura, B. S.; Condie, A. G.; Buff, R. C.; Karahalis, G. J.; Stephenson, C. R. J. Org. Lett. 2011, 13, 6320.

(24) (a) Wang, J.; Soisson, S. M.; Young, K.; Shoop, W.; Kodali, S.; Galgoci, A.; Painter, R.; Parthasarathy, G.; Tang, Y. S.; Cummings, R.; Ha, S.; Dorso, K.; Motyl, M.; Jayasuriya, H.; Ondeyka, J.; Herath, K.; Zhang, C.; Hernandez, L.; Alloco, J.; Basilio, A.; Tormo, J. R.; Genilloud, O.; Vicente, F.; Pelaez, F.; Colwell, L.; Lee, S. H.; Michael, B.; Felcetto, T.; Gill, C.; Silver, L. L.; Hermes, J. D.; Bartizal, K.; Barret, J.; Schmatz, D.; Becker, J. W.; Cully, D.; Singh, S. B. Nature 2006, 441, 358. (b) Saleem, M.; Hussain, H.; Ahmed, I.; van Ree, T.; Krohn, K. Nat. Prod. Rep. 2011, 28, 1534.

(25) (a) Hegedus, L. S.; Allen, G. F.; Waterman, E. L. J. Am. Chem. Soc. 1976, 98, 2674. (b) Hayashi, T.; Hegedus, L. S. J. Am. Chem. Soc. 1977, 99, 7093. (c) Hegedus, L. S.; Allen, G. F.; Bozell, J. J.; Waterman, E. L. J. Am. Chem. Soc. 1978, 100, 5800. (d) Semmelhack, M. F.; Bodurow, C. J. Am. Chem. Soc. 1984, 106, 1496. (e) Semmelhack, M. F.; Zhang, N. J. Org. Chem. 1989, 54, 4483. (f) Semmelhack, M. F.; Epa, W. R. Tetrahedron Lett. 1993, 34, 7205. (g) Wolfe, J. P.; Rossi, M. A. J. Am. Chem. Soc. 2004, 126, 1620. (h) Lira, R.; Wolfe, J. P. J. Am. Chem. Soc. 2004, 126, 13906. (i) Leathen, M. L.; Rosen, B. R.; Wolfe, J. P. J. Org. Chem. 2009, 74, 5107. (j) Rosen, B. R.; Ney, J. E.; Wolfe, J. P. J. Org. Chem. 2010, 75, 2756. (k) Bloome, K. S.; Alexanian, E. J. J. Am. Chem. Soc. 2010, 132, 12823.

(26) Pouységu, L.; Sylla, T.; Garnier, T.; Rojas, L. B.; Charris, J.; Deffieux, D.; Quideau, S. Tetrahedron 2010, 66, 5908.

(27) Carman, R. M.; Lambert, L. K.; Robinson, W. T.; Van Dongen, J. M. A. M. Aust. J. Chem. 1986, 39, 1843.

(28) Hoarau, C.; Pettus, T. R. R. Org. Lett. 2006, 8, 2843.

(29) Mejorado, L. H.; Hoarau, C.; Pettus, T. R. R. Org. Lett. 2004, 6, 1535.

(30) Vo, N. T.; Pace, R. D. M.; O'Hara, F.; Gaunt, M. J. J. Am. Chem. Soc. 2008, 130, 404.

(31) Gu, Q.; You, S. Chem. Sci. 2011, 2, 1519.

(32) (a) Popelak, A.; Haack, E.; Lettenbauer, G.; Spingler, H. Naturwissenschaften 1960, 47, 156. (b) Smith, E.; Hosansky, N.; Shamma, M.; Moss, J. B. Chem. Ind. 1961, 402.

(33) Gu, Q.; You, S. Org. Lett. 2011, 13, 5192.

(34) Nemoto, T.; Ishige, Y.; Yoshida, M.; Kohno, Y.; Kanematsu, M.; Hamada, Y. Org. Lett. 2010, 12, 5020.

(35) Liang, H.; Ciufolini, M. A. Angew. Chem. Int. Ed. 2011, 50, 11849. 
(36) Dohi, T.; Maruyama, A.; Takenaga, N.; Senami, K.; Minamitsuji, Y.; Fujioka, H.; Caemmerer, S. B.; Kita, Y. Angew. Chem. Int. Ed. 2008, 47, 3787.

(37) (a) Lewis, N.; Wallbank, P. Synthesis 1987, 1103. (b) Barret, R.; Daudon, M. Tetrahedron Lett. 1990, 31, 4871. (c) Mal, D.; Roy, H. N.; Hazra, N. K.; Adhikari, S. Tetrahedron 1997, 53, 2177. (d) Quideau, S.; Pouységu, L.; Oxoby, M.; Looney, M. A. Tetrahedron 2001, 57, 319. (e) Wood, J. L.; Graeber, J. K.; Njardarson, J. T. Tetrahedron 2003, 59, 8855.

(38) (a) Pelter, A.; Elgendy, S. Tetrahedron Lett. 1988, 29, 677. (b) Kürti, L.; Herczegh, P.; Visy, J.; Simonyi, M.; Antus, S.; Pelter, A. J. Chem. Soc., Perkin Trans. 1 1999, 379.

(c) Pelter, A.; Ward, R. S. Tetrahedron 2001, 57, 273.

(39) (a) Uyanik, M.; Yasui, T.; Ishihara, K. Angew. Chem. Int. Ed. 2010, 49, 2175. (b) Uyanik, M.; Yasui, T.; Ishihara, K. Tetrahedron 2010, 66, 5841 .

(40) Quideau, S.; Lyvinec, G.; Marguerit, M.; Bathany, K.; Ozanne-Beaudenon, A.; Buffeteau, T.; Cavagnat, D.; Chénedé, A. Angew. Chem. Int. Ed. 2009, 48, 4605.

(41) Boppisetti, J. K.; Birman, V. B. Org. Lett. 2009, 11, 1221.

(42) Li, F.; Tartakoff, S. S.; Castle, S. L. J. Am. Chem. Soc. 2009, 131,6674 .

(43) (a) Mendelsohn, B. A.; Lee, S.; Kim, S.; Teyssier, F.; Aulakh, V. S.; Ciufolini, M. A. Org. Lett. 2009, 11, 1539. (b) Mendelsohn, B. A.; Ciufolini, M. A. Org. Lett. 2009, 11, 4736.

(44) Frie, J. L.; Jeffrey, C. S.; Sorensen, E. J. Org. Lett. 2009, 11, 5394.

(45) For a review covering the oxidation of oximes to nitrile oxides with hypervalent iodine reagents, see: Turner, C. D.; Ciufolini, M. A. ARKIVOC 2011, (i), 410.

(46) Mejorado, L. H.; Pettus, T. R. R. J. Am. Chem. Soc. 2006, $128,15625$.

(47) Green, J. C.; Pettus, T. R. R. J. Am. Chem. Soc. 2011, 133, 1603.

(48) Krawczuk, P. J.; Schne, N.; Baran, P. S. Org. Lett. 2009, 11, 4774.

(49) Mehta, G.; Maity, P. Tetrahedron Lett. 2007, 48, 8865.

(50) (a) Zhu, J.; Grigoriadis, N. P.; Lee, J. P.; Porco, J. A. Jr. J. Am. Chem. Soc. 2005, 127, 9342. (b) Zhu, J.; Porco, J. A. Jr. Org. Lett. 2006, 8, 5169.
(51) Dong, S.; Hamel, E.; Bai, R.; Covell, G. D.; Beutler, J. A.; Porco, J. A. Jr Angew. Chem. Int. Ed. 2009, 48, 1494.

(52) Hu, Y.; Li, C.; Kulkarni, B. A.; Strobel, G.; Lobkovsky, E.; Torczynski, R. M.; Porco, J. A. Jr. Org. Lett. 2001, 3, 1649.

(53) Dohi, T.; Minamitsuji, Y.; Maruyama, A.; Hirose, S.; Kita, Y. Org. Lett. 2008, 10, 3559.

(54) Nicolaou, K. C.; Edmonds, D. J.; Li, A.; Tria, G. S. Angew. Chem. Int. Ed. 2007, 46, 3942.

(55) Sabot, C.; Guérard, K. C.; Canesi, S. Chem. Commun. 2009, 2941.

(56) Dai, M.; Danishefsky, S. J. Tetrahedron Lett. 2008, 49, 6610.

(57) Wang, X.; Porco, J. A. Jr. Angew. Chem. Int. Ed. 2005, 44, 3067.

(58) (a) Baxendale, I. R.; Ley, S. V.; Piutti, C. Angew. Chem. Int. Ed. 2002, 41, 2194. (b) Baxendale, I. R.; Ley, S. V.; Nessi, M.; Piutti, C. Tetrahedron 2002, 58, 6285.

(59) Baxendale, I. R.; Ley, S. V. Ind. Eng. Chem. Res. 2005, 44, 8588 .

(60) Heckrodt, T. J.; Mulzer, J. J. Am. Chem. Soc. 2003, 125, 4680.

(61) Burgett, A. W. G.; Li, Q.; Wei, Q.; Harran, P. G. Angew. Chem. Int. Ed. 2003, 42, 4961.

(62) (a) Yasui, Y.; Suzuki, K.; Matsumoto, T. Synlett 2004, 619. (b) Yasui, Y.; Koga, Y.; Suzuki, K.; Matsumoto, T. Synlett 2004, 615 .

(63) Onoda, T.; Takikawa, Y.; Fujimoto, T.; Yasui, Y.; Suzuki, K.; Matsumoto, T. Synlett 2009, 1041.

(64) Ciufolini, M. A.; Braun, N. A.; Canesi, S.; Ousmer, M.; Chang, J.; Chai, D. Synthesis 2007, 3759.

(65) Ousmer, M.; Braun, N. A.; Ciufolini, M. A. Org. Lett. 2001, 3,765 .

(66) (a) Ciufolini, M. A.; Canesi, S.; Ousmer, M.; Braun, N. A. Tetrahedron 2006, 62, 5318. (b) Ousmer, M.; Braun, N. A.; Bavoux, C.; Perrin, M.; Ciufolini, M. A. J. Am. Chem. Soc. 2001, 123, 7534.

(67) Canesi, S.; Bouchu, D.; Ciufolini, M. A. Angew. Chem. Int. Ed. 2004, 43, 4336.

(68) Scheffler, G.; Seike, H.; Sorensen, E. J. Angew. Chem. Int. Ed. 2000, 39, 4593.

(69) Mizutani, H.; Takayama, J.; Soeda, Y.; Honda, T. Tetrahedron Lett. 2002, 43, 2411. 